\title{
WHICH SHORTS ARE INFORMED?
}

\author{
Ekkehart Boehmer \\ Mays Business School \\ Texas A\&M University \\ Charles M. Jones \\ Graduate School of Business \\ Columbia University \\ Xiaoyan Zhang \\ Johnson Graduate School of Management \\ Cornell University
}

This draft: November 11, 2005

We are grateful to Yakov Amihud, Amy Edwards, Joel Hasbrouck, Terry Hendershott, Owen Lamont, Mark Seasholes, Sorin Sorescu, Michela Verardo, Ingrid Werner, and seminar participants at Cornell, Goldman Sachs Asset Management, the London School of Economics, the NBER Market Microstructure meeting, and the NYSE for helpful comments. We thank the NYSE for providing system order data. 


\title{
WHICH SHORTS ARE INFORMED?
}

\begin{abstract}
We use a long, recent panel of proprietary system order data from the New York Stock Exchange to examine the incidence and information content of various kinds of short sale orders. On average, at least $12.9 \%$ of NYSE volume involves a short seller. As a group, these short sellers are extremely well-informed. Stocks with relatively heavy shorting underperform lightly shorted stocks by a risk-adjusted average of $1.07 \%$ in the following 20 days of trading (over $14 \%$ on an annualized basis). Large short sale orders are the most informative. In contrast, when more of the short sales are small (less than 500 shares), stocks tend to rise in the following month, indicating that these orders are uninformed. We partition short sales by account type: individual, institutional, member-firm proprietary, and other, and we can distinguish between program and non-program short sales. Institutional non-program short sales are the most informative. Compared to stocks that are lightly shorted by institutions, a portfolio of stocks most heavily shorted by institutions on a given day underperforms by a risk-adjusted average of $1.36 \%$ in the next month (over 18\% annualized). These alphas do not account for the cost of shorting, and they cannot be achieved by outsiders, because the internal NYSE data that we use are not generally available to market participants. But these findings indicate that institutional short sellers have identified and acted on important value-relevant information that has not yet been impounded into price. The results are strongly consistent with the emerging consensus in financial economics that short sellers possess important information, and their trades are important contributors to more efficient stock prices.
\end{abstract}




\section{WHICH SHORTS ARE INFORMED?}

A number of theoretical models, beginning with Miller (1977) and Harrison and Kreps (1978), show that when short selling is difficult or expensive, stocks can become overvalued as long as investors agree to disagree on valuations. There is a horde of much more recent empirical evidence which uniformly supports this proposition. There is now a consensus, at least in the financial economics literature if not on Main Street, that short sellers occupy a fairly exalted position in the pantheon of investors for their role in keeping prices in line.

But there is surprisingly little direct evidence that short sellers know what they are doing, that they are any different from or better informed about fundamentals than other investors. There is plenty of indirect evidence. For example, Aitken et al. (1998) show that in Australia, where short sales are immediately disclosed to the public, the reporting of a short sale causes prices to decline immediately. Jones and Lamont (2002) show that when the price of shorting rises (indicating either an increase in shorting demand or a decline in the supply of lendable shares), stock prices soon fall. Cohen, Diether, and Malloy (2005) cleverly separate these two and show that it is the increase in shorting demand that is associated with an eventual fall in stock prices. Dechow et al. (2001) find that short sellers generate positive abnormal returns by targeting companies that are overpriced based on fundamental ratios such as P/E and market-tobook. In the last case, changes in shorting demand are inferred from successive monthly short interest snapshots rather than observed directly in transactions data.

Researchers, regulators, and other observers tend to lump short sellers together as a homogeneous group. But just like other investors, there are many different kinds of short sellers, with differing motivations for shorting a stock. Naturally, some short sellers take their positions based on fundamental information about a company's valuation, either on an absolute basis or relative to other firms. In contrast, convertible arbitrage hedge funds and options market-makers might short a stock as part of their hedging strategy, with little thought to whether the stock itself is over- or undervalued. Index arbitrageurs might long futures or some other basket instrument and short the underlying stocks. Market-makers might short shares as a part of their regular buffering activity. Some of these shorts are based on information or opinions about the firm's share price level; some are not. Thus, it seems important to distinguish between these different types of shorts. 
In this paper, we use a long panel of proprietary data from the New York Stock Exchange (NYSE) that identifies all short sale orders submitted electronically to the exchange. Among other things, the data identify the type of customer initiating the short. These account type data are not overly detailed, but they do distinguish between individuals, institutions, and member firm proprietary trades, and we can tell if a short sale was executed as part of a program trade. This allows us to explore which of these groups, if any, possess private information about equity values.

In the world of shorting, it is not obvious that institutions are better informed than individuals. It is popular to regard individual stock trading as less informed and even irrational, and there is plenty of supporting evidence. But few individual traders sell short, and those who do are likely to be the most sophisticated, knowledgeable investors. It is also easy to imagine that at least some negative private information is endowed (which is perhaps more likely for individuals) rather than acquired through costly research (the likely avenue for institutions). As part of their regular job duties, certain individuals, such as corporate insiders, suppliers, and the like, might simply know when things are not going well at a given firm. Corporate insiders are forbidden from shorting their own stocks, but others are less restricted. And even corporate insiders might take short positions in companies that are close substitutes. An airline executive with negative information about the whole industry could easily profit from his information by shorting his competitors' stocks. With our data, we can for the first time compare the information possessed by these two groups of short sellers.

Most of the empirical data on short selling is about the price or quantity of shorting. There are many potential costs associated with shorting, but the clearest pecuniary cost is associated with the rebate rate. To initiate a short position, a short seller must deliver shares to the buyer and thus must borrow shares. To collateralize the loan, the share lender requires that the short seller deposit the proceeds of the short with the lender. The share lender pays interest on this deposit, and the interest rate is called the rebate rate. For most stocks, the rebate rate is very close to other overnight interest rates, and for these stocks the short seller loses little from not having access to the proceeds of his short. In certain cases, where shorting demand is greater or the supply of lendable shares is small, the rebate rate may fall to zero or even become negative, and this reduction in the rebate rate is a direct cost of selling short. A number of authors have been able to obtain rebate rates from major custodians and share lenders, including 
D’Avolio (2002) Geczy, Musto, and Reed (2002), Ofek and Whitelaw (2003), and Cohen, Diether, and Malloy (2005). Jones and Lamont (2002) assemble a long panel of rebate rates from the 1920's and 1930's, when centralized share lending took place at a post on the NYSE trading floor. Shorting costs can also be inferred indirectly. For example, Ofek, Richardson, and Whitelaw (2004) look at violations of put-call parity in an equity option as an indication that it has become costly to short that particular stock. There are other potential costs of shorting as well, such as recall risk if the share lender chooses to terminate the loan and another share lender cannot be found. These are more difficult to quantify, though Evans et al. (2003) study the resulting so-called buy-ins and assert that the costs associated with recalls are quite small.

Quantity data are the other major type of empirical data, and these quantities are almost always stock rather than flow data. The most common sources for quantities in the U.S. are the monthly short interest reports of the major exchanges. The evidence is mixed on whether these short interest reports can be used by an investor to earn excess returns. For example, Brent, Morse, and Stice (1990) find that monthly short interest does not predict either the cross-section or time-series behavior of returns, Asquith, Pathak, and Ritter (2004) find predictive power only in the smallest stocks, while authors such as Asquith and Meulbroek (1996) and Desai et al. (2001) find more evidence of predictive power. Lamont and Stein (2004) find that aggregate short interest is extrapolative, reacting to past price moves, but has no predictive power for future market moves.

Our data are also quantity measures, but of the flow of shorting rather than the stock of shorting. This has a number of advantages. First of all, our data are much finer than traditional monthly short interest data. We have the ability to examine daily or even intraday data on short sales. If many shorts maintain their positions for only a short period of time, daily flow data may be an improvement over coarse monthly short interest data. Jones (2004) provides evidence that indicates that short-lived shorts could be prevalent, albeit from the early 1930's. During that period, shorting and covering on the same day - known at the time as "in-and-out shorting" averaged about $5 \%$ of total daily volume, and a much bigger (but unknown) fraction of overall shorting activity.

A second advantage of order level data is that we can identify many of the characteristics of executed orders, such as the account type and order type (e.g., market vs. limit order). Finally, we can also examine short sale orders that remain unexecuted for whatever reason and are later 
cancelled. In this paper, we mainly exploit the account type originating the short sale order. There are four different types of accounts: individual, institution, member-firm proprietary, and other. The account type partitions are:

\begin{tabular}{ll} 
Account Type Designation & Description \\
\hline Individual & $\begin{array}{l}\text { Agency orders that originate from } \\
\text { individuals }\end{array}$ \\
Institution & $\begin{array}{l}\text { Agency orders that do not originate with } \\
\text { individuals. }\end{array}$ \\
& Orders where NYSE members are trading as \\
principal. Excludes all trades by the & specialist for his own account. \\
& Includes orders by market-makers from \\
Options and other markets.
\end{tabular}

We further partition institutional and proprietary short sales depending on whether the order is part of a program trade. A program trade is defined as simultaneous orders to trade 15 or more stocks having an aggregate total value of at least \$1 million. There is some incentive for institutions to batch their trades to qualify as a program trade, because program trades are often eligible for commission discounts from brokers.

Account types are coded by the submitting broker-dealer based on a set of regulations issued by the NYSE. While they are generally unaudited, these classifications are important to the NYSE and to broker-dealers because they are required for a number of compliance issues. For example, NYSE Rule 80A suspends certain types of index arbitrage program trading on volatile trading days, and account type classifications are important for enforcing this ban. The specialist and traders on the floor do not, however, observe this account type indicator for an incoming system order. In general, these market participants observe only the type, size, and limit price (if applicable) of an order. It is possible for the specialist to research a particular order in real-time and obtain information about the submitting broker. However, this takes a number of keystrokes and requires a certain amount of time, and given the pace of trading on the exchange and our conversations with specialists, we conclude that this additional information is seldom if ever observed before execution.

In contrast, during our sample period the specialist is always aware that a particular system sell order is a short sale. For compliance with the uptick rule, short sales must be marked, and during our sample period software at the trading post flags every short sale order to 
help the specialist comply with the uptick rule. ${ }^{1}$ Should the uptick rule become binding on an order to short sell, the display book software enforces a limit price to comply with the uptick rule. This means that the specialist might be one of the few market participants with an ability to incorporate this information into trading strategies, though a specialist's market-making obligations would constrain his ability to exploit this information fully.

To our knowledge, we are the first academic researchers to partition short sales by account type. NYSE account types have been used in a handful of other related papers. For example, Kaniel, Saar, and Titman (2004) use NYSE account types to investigate investor sentiment, and Boehmer and Kelley (2005) use account types to investigate the relationship between efficient prices and the amount of institutional trade. Other authors who study shorting flow data include Christophe, Ferri, and Angel (2004), Daske, Richardson, and Tuna (2005), and Diether, Lee, and Werner (2005), but all these panels are much shorter than ours and do not distinguish among different trader types.

We also observe other aspects of the short-sale order, notably the order size. In looking at all trades, both Barclay and Warner (1993) and Chakravarty (2001) find that medium-size orders are the most informed, which they label the stealth-trading hypothesis. When we look at large vs. small short sale orders, we find somewhat different results. Like these earlier researchers, we find that small short sale orders are on average uninformed, and medium-sized short sale orders of 500 to 5,000 shares are more informed. In contrast to the stealth trading findings, however, we find that the largest short sale orders (those of at least 10,000 shares) are the most informative about future price moves. Thus, it appears that informed short sellers use larger orders than other informed traders.

It is worth pointing out that there are two aspects of shorting flow we do not observe in our data. First, we do not observe short covering in our dataset. We can see additions to short interest, but not the subtractions, so we are unable to use our data to impute the level of short interest between the monthly publication dates. Also, we do not observe all of the short sales that take place. We observe all short sale orders that are submitted electronically or otherwise routed through the NYSE SuperDOT system. We do not observe short sales that are manually

\footnotetext{
${ }^{1}$ This is no longer the case for Regualation SHO pilot stocks where the uptick rule has been suspended. Short sale orders in these NYSE stocks must still be marked by the submitting broker, but these are masked by the NYSE's display book software, which means the specialist and floor are unable to observe which sell orders are shorts.
} 
executed on the NYSE trading floor by a floor broker. Also, we do not observe short sales that take place away from the NYSE. Short sales executed on regional exchanges, in the upstairs market, or offshore are not included in this sample, nor are shorts created synthetically using total return swaps or other derivatives. Nevertheless, we believe that our sample captures a substantial fraction of shorting activity, and our aim in this paper is to explore the informativeness of this order flow.

As stated above, we observe all short sale orders that are submitted to the NYSE trading floor via electronic means. While we do not know exactly what fraction of total shorting is executed this way, based on overall volume figures we do know that system order data capture a substantial fraction of overall trading activity. According to the NYSE online fact book at nysedata.com, during 2002 shares executed via the NYSE SuperDOT system are 70.5\% of NYSE volume. If short sale orders are routed and executed similarly, our sample would account for $70.5 \%$ of all short sales in 2002. Of course, we cannot be sure that this is so. Given the uptick rule, short sellers may prefer the hands-on order management of a floor broker. ${ }^{2}$ Short sales may also be executed in London or elsewhere outside the United States to avoid domestic restrictions. As part of Regulation SHO, which came into effect at the beginning of 2005, all US market venues must release trade-by-trade data indicating which trades are short sales. Until those data become widely available, we claim only that our dataset is big and not necessarily representative of all short sales.

The paper is structured as follows. Section 1 discusses the sample in more detail, both in terms of overall shorting flow and the account type subdivisions. Section 2 examines the information in aggregate shorting flow for the cross-section of future stock returns. Subsections use shorting flow from different account types and different order sizes to see which kinds of short sales are most informative about the cross-section of future returns. Section 3 conducts a number of robustness tests. One must be careful in interpreting the empirical results, and this is the focus of Section 4. Section 5 concludes.

\footnotetext{
${ }^{2}$ During our sample period, the uptick rule applied to all stocks listed on the NYSE and AMEX. The rule applies to most short sales and requires them to execute at a price that is either (a) higher than the last sale price (an uptick), or (b) the same as the last sale price, if the most recent price change was positive (a zero-plus tick).
} 


\section{Sample and Summary Statistics}

The sample consists of all NYSE system order data records related to short sales from January 2000 through April 2004. We cross-match to CRSP and retain only common stocks, which means we exclude securities such as warrants, preferred shares, ADRs, closed-end funds, and REITs. ${ }^{3}$ This leaves us a daily average of 1,239 NYSE-listed common stocks. For each trading day, we aggregate all short sales in each stock that are subject to the uptick rule. A few short sales are exempt from the uptick rule. These include relative-value trades between stocks and convertible securities, arbitrage trades in the same security trading in New York vs. offshore markets, and short sales initiated by broker-dealers at other market centers as a result of bona fide market-making activity. These exempt short sales are marked separately in the system order data, and their share volume amounts to only $1.5 \%$ of total shorting volume in our sample. We exclude these orders because they are less likely to reflect negative fundamental information about the stock.

We measure shorting flow three different ways. First, we simply count the number of short sale transactions in a given stock on a given day, regardless of size. Jones, Kaul, and Lipson (1994) find that the number of trades, rather than total volume, is most closely associated with the magnitude of price changes, and our use of the number of short sale trades is in the same spirit. Our second measure is the total number of shares sold short in a given stock on a given day. Our final measure is the fraction of volume executed on the NYSE in a given stock on a given day that involves a system short seller.

Table 1 Panels A and B provide summary statistics about overall shorting flow measures, undifferentiated by account type. NYSE common stocks experience an average of 146 short-sale transactions in a given day, with a mean of 99,747 shares sold short via system orders per stock per day. Note that a small number of stocks account for most of the shorting, as the median stock has 27,425 shares sold short daily and the $75^{\text {th }}$ percentile of 95,417 shares per day is still below the mean.

One striking result is that shorting via system orders averages $12.86 \%$ of overall NYSE trading volume (equal-weighted across stocks). Recall that this is a lower bound on the

\footnotetext{
${ }^{3}$ Some care is required in matching stocks. NYSE data, including both SOD and TAQ, use the ticker symbol as the primary identifier. However, ticker symbols are often reused, and ticker symbols in CRSP do not always match the ticker symbols in NYSE data, especially for firms with multiple share classes. We use tickers and CUSIPs to ensure accurate matching.
} 
incidence of shorting, since our sample does not include specialist short sales or short sales that are handled by a floor broker. Nevertheless, this number is somewhat surprising, since aggregate short interest in NYSE stocks during 2004 is only $2.0 \%$ of shares outstanding. The short interest numbers suggest that shorting is relatively uncommon, while the shorting flow numbers indicate that shorting is quite pervasive. The dichotomy between these two numbers also means that short positions are on average shorter-lived than long positions. To see this, note first that if shareholders are homogeneous (so there is no Jensen's inequality effect), then:

$$
D_{i}=1 / T_{i},
$$

where $D_{i}$ is the length of time between opening and unwinding a position in stock $i$, and $T_{i}$ is the turnover (shares traded / shares outstanding) in stock $i$. For example, if $1 \%$ of the shares trade each day, then it takes 100 days for the entire stock of outstanding shares to turn over, and the average holding period is 100 days. Assuming a constant short interest and homogeneity, the same relationship holds for the subset of positions held by shorts or longs:

Duration of short positions $=$ short interest in shares $/$ shorting volume in shares

Duration of long positions = total long positions / non-shorting volume $=$ (shares outstanding + short interest $) /$ non-short volume in shares In 2004, for example, based on aggregate data from the NYSE online fact book, aggregate short interest averages 7.6 million shares, while aggregate shorting volume totals 51.2 million shares for the year, which means that the average short position lasts $7.6 / 51.2=0.15$ years, or about 37 trading days. In contrast, the average duration for a long position is 1.20 years. The dichotomy is similar when we use our sample of short sales instead of all short sales. These dramatic differences in duration suggest that short selling is dominated by short-term trading strategies.

Panel B shows contemporaneous correlations, first-order autocorrelations and crossautocorrelations of our various daily shorting measures along with stock returns, pooling the entire daily panel. All three shorting flow measures are positively correlated, with correlations ranging from 0.20 to 0.71 . The number of short transactions and the number of shares sold short are strongly positively correlated $(\rho=0.71)$. These measures are not standardized in any way, and so it is not surprising that they are less strongly correlated with shorting's share of total volume, which is standardized. All the measures are strongly persistent, with first-order autocorrelations between 0.52 and 0.84 . Finally, note the suggestive evidence in these simple correlations that short sellers trade to keep prices in line. While the magnitudes are small, the 
cross-sectional correlation is positive between shorting activity in a stock and that stock's return on the same or previous day, while the correlation with the next day's return is negative (and these correlations are statistically different from zero).

Panel D sorts stocks into 25 size and book-to-market portfolios and measures average shorting activity within each portfolio. Most notable is shorting's share of overall trading volume, at the bottom of the panel. There are no strong patterns either across or down the panel, as the mean shorting share varies only modestly from $10.5 \%$ to $15.2 \%$ of overall NYSE trading volume. Consistent with short interest data, there is a bit less shorting of small firms, but even there shorting is quite prevalent. While there may still be costs or impediments to short selling, these numbers suggest that many market participants are overcoming these hurdles, even in the smallest NYSE stocks. It could be that these are inframarginal short sales, and the constraints continue to bind for some market participants. But the pervasiveness of shorting suggests that shorting constraints are not very severe, at least for stocks in the NYSE universe.

\section{The cross-section of shorting and future returns}

\section{A. Simple sorts}

If short sellers are informed, the stocks they short heavily should underperform the stocks they avoid shorting. One way to measure this information content is to calculate an average price impact for short sales, which is just the average proportional price decline over some interval following a short sale. However, if a certain amount of shorting is uninformed and present in all stocks, the average price impact of a short sale may not be as interesting as the cross-sectional differences between stocks that are heavily vs. lightly shorted. To study these cross-sectional differences, we adopt a portfolio approach. A portfolio approach also has other advantages. First, it is easy to interpret, because it replicates the gross and/or risk-adjusted returns to a potential trading strategy, assuming (counterfactually) that one could observe these shorting flow data in real time. Second, compared to a regression approach the aggregation into portfolios can reduce the impact of outliers. Finally, portfolios are better able to capture any non-linearities that might characterize the relationship between shorting activity and future returns.

Thus, in the time-honored asset pricing tradition, we begin by sorting stocks into portfolios based on our shorting flow measures. Each day, we sort into quintiles based on 
shorting activity during the previous five trading days. The four middle columns of Table 2 Panel A shows how these sorts are correlated with other stock characteristics that have been studied previously. Shorting activity is positively correlated with trading volume, no matter how the shorting is measured. Shorting does not seem to be strongly correlated with daily stock return volatility, however. The unstandardized shorting measures (number of trades and shares sold short) are strongly positively correlated to size. This is unsurprising, because large cap stocks simply have more shares outstanding, and one would expect more trading and thus more shorting of these stocks. The standardized shorting measure (shorting's share of volume) has the opposite correlation to market cap. On average, large stocks tend to experience light shorting by these measures. There is not much of a relationship between the shorting flow measures and book-to-market ratios. As might be expected, more shorting activity is found in stocks that have high market values relative to book. For example, the quintile with the smallest number of shares shorted has an average book-to-market ratio of 0.77 , while the heavily shorted quintile has a book-to-market ratio of 0.60. Average book-to-market differences are even smaller for shorting's share of overall trading volume. Thus, there is at best only weak evidence that short sellers target stocks with high market-to-book as potentially overpriced. As one might expect, uncovering a mispriced stock involves more than just studying book vs. market values.

After firms are sorted into quintiles each day, the four right-most columns of Panel A show the average cumulative value-weighted return over the next 20 trading days (approximately one calendar month). The basic result is that short sellers are well-informed over this horizon. ${ }^{4}$ Most notable is the next month's value-weighted return on heavily shorted stocks (quintile 5) vs. the return on lightly shorted stocks (quintile 1). The raw returns on heavily shorted stocks are quite low, averaging only $0.02 \%$ or $0.03 \%$ per month for those stocks with the most shorting trades or shorted shares. In contrast, the corresponding portfolios of lightly shorted stocks generate returns of at least $2.60 \%$ over the next 20 trading days. These numbers suggest that short sellers are good at relative valuation, and are particularly good at avoiding shorting undervalued stocks. However, short sellers are not necessarily identifying stocks that are overvalued on an absolute basis. Like the simple correlations discussed in Table 1, this suggests

\footnotetext{
${ }^{4}$ Shorting flow also contains information about future returns at shorter horizons, but it appears to take a full 20 trading days for the information behind shorting flow to be fully incorporated into prices. This is discussed further in Section 2.C.
} 
that perhaps it is better to think of short sellers as keeping prices in line rather than bringing prices back into line.

Looking at the return differences, heavily shorted stocks underperform lightly shorted stocks, no matter what shorting measure is used. We focus on shorting's share of overall trading volume, because this measure is the most orthogonal to size, book-to-market, and trading activity, each of which has been shown to be related to average returns. Using this shorting measure, the raw return difference between the heavily shorted quintile and the lightly shorted quintile is a statistically significant $0.55 \%$ per month (7.16\% per year annualized). Because new portfolios are formed daily, while the holding period is 20 trading days, the holding period returns overlap out to lag 20. Statistical inference accounts for this overlap using Newey-West standard errors with 20 lags.

Even though we are sorting on a measure that is mostly orthogonal to size and book-tomarket, these portfolios could still have different exposures to priced risks. To risk-adjust, we calculate Fama-French alphas on each portfolio and compare the extreme quintiles. To be more precise, for each quintile portfolio, we have daily observations of 20-day holding period returns over the entire sample. We subtract the riskless rate and regress these 20-day excess returns on the three contemporaneous Fama-French factors (RMRF, SMB, and HML), and the residuals are the Fama-French alphas for each 20-day holding period. Because these holding periods overlap, we conduct inference using Newey-West standard errors with 20 lags. On a risk-adjusted basis, the heavily shorted stocks underperform lightly shorted stocks by an average of 1.07\% per month, or $14.35 \%$ annualized. Even though the sample is only $41 / 3$ years long, the average return difference is highly statistically significant, with a t-statistic of 5.10.

The sample period includes the bursting of the so-called Nasdaq bubble, with sharp declines in technology firm stock prices. One might worry that the results here are driven by those tech stock declines. Note that the sample is already limited to NYSE firms, which excludes the vast majority of technology stocks already. But there are some prominent technology stocks listed on the NYSE, such as AOL Time Warner. To investigate this possibility, we partition the sample into tech vs. non-tech firms using the SIC codes in Loughran and Ritter (2004) and recalculate return differences based on shorting activity. The results are in Table 2 Panel B, and there is no evidence that the results are driven by technology stocks. For some shorting measures, the return differences are bigger for tech firms, and for other shorting 
measures, the return differences are smaller. More importantly, for non-tech firms the difference in Fama-French alphas between heavily shorted and lightly shorted stocks is always significant, ranging from $1.24 \%$ to $1.69 \%$ per month depending on the shorting activity measure.

\section{B Double sorts}

We continue with another set of robustness checks. To determine whether shorting activity constitutes a new cross-sectional regularity, we conduct double sorts based on characteristics known to be associated with returns. Note that some of these other characteristics are not available at high frequencies, so we first sort stocks into quintiles based on size, marketto-book, stock return volatility, or turnover for the previous month. Within a characteristic quintile, we then sort a second time into quintiles each day based on shorting flow over the past five trading days. The result is a set of stocks that differ in shorting activity but have similar size, market-to-book, volatility, or turnover.

Average value-weighted returns are calculated for each portfolio over the next 20 days, and we report in Table 3 the value-weighted risk-adjusted return difference between the heavily shorted and lightly shorted quintiles. Again, because these portfolio holding periods overlap, we conduct inference using Newey-West standard errors with the appropriate number of lags. Return differences are reported for each of the shorting activity measures.

Table 3 Panel A controls for the firm's market capitalization. The shorting effect is present across all five size quintiles. This differs from the results in Diether, Lee, and Werner (2005) probably because we have a much longer sample period and thus greater statistical power. The results are strongest for the smallest quintile, where heavily shorted stocks underperform lightly shorted stocks by $2.23 \%$ to $3.29 \%$ per month. The shorts' information advantage makes sense given the relative paucity of research coverage and other readily available sources of information about small cap firms. Based on the evidence in Table 1 Panel D, even small stocks experience significant shorting activity, so it is certainly possible for some investors to short these stocks. However, small stocks may be expensive to short (see, for example, the evidence in Geczy, Musto, and Reed (2002)), and it is important to remember that the return differences throughout this paper do not account for any potential costs of shorting. Interestingly, the shorting effect is also fairly strong for the large-cap quintile, with excess returns between $0.65 \%$ and $1.01 \%$ per month, depending on the shorting measure. This is striking because many so- 
called anomalies in finance do not appear in large-cap stocks, but the evidence here indicates that short sellers as a group are earning substantial excess returns even on bellwether stocks. We also perform a closely related double sort, first on institutional ownership (based on SEC 13f filings) and then on shorting flow. We do not report these results in detail, but, in contrast to the shortinterest evidence in Asquith, Pathak, and Ritter (2005), heavily shorted stocks underperform lightly shorted stocks across all institutional ownership quintiles. This provides additional evidence that shorts are informed across a wide spectrum of NYSE firms.

In Table 3 Panel B, we sort first by book-to-market and then by shorting activity. Our prior here was that low book-to-market might be a necessary but not sufficient condition for a stock to be overvalued. If true, then short sellers might further evaluate these stocks, identify those low book-to-market stocks that are indeed overvalued, and short them heavily. If the short sellers are correct, these heavily shorted stocks will eventually experience negative returns.

This is only partially borne out in the data. For stocks in the lowest book-to-market quintile, shorting activity does have strong predictive power for the cross-section of returns in the following month. Stocks with the most short sale transactions underperform those with the fewest orders by $1.51 \%$ per month. Sorting by the number of shares shorted gives a return difference of $1.36 \%$ per month, and sorting by shorting's share of volume gives a return difference of $0.89 \%$. All of these are highly statistically significant.

In contrast to our priors, shorting activity seems to predict next month's returns across all book-to-market quintiles, and in fact may be slightly stronger in the highest book-to-market quintiles. Again, the effect is strongest for the number of short transactions and the number of shares shorted. For these shorting measures, heavily shorted stocks always far underperform lightly shorted stocks, with return differences in the $2 \%$ to $3 \%$ range per month. For our preferred measure - shorting's share of overall volume - the excess return differences are quite similar across all five book-to-market quintiles, ranging from $0.89 \%$ to $1.61 \%$ per month. We conclude from this that low book-to-market is neither a necessary nor sufficient condition for a stock to be overvalued. It appears that short sellers are able to identify overvalued stocks across the book-to-market spectrum, with stocks underperforming in the month after heavy shorting.

In Table 3 Panel C we control for individual stock return volatility. Ang, Hodrick, Xing, and Zhang (2004) find that firms with volatile stock returns severely underperform on a riskadjusted basis. One might guess that the volatility effect might be related to our short-selling 
effect, if the volatility reflects severe differences of opinion and thus heavy (and ex post informed) short selling. However, the data indicate that the volatility effect does not chase out the return differences based on shorting activity. ${ }^{5}$ For both low volatility and high volatility firms, heavy shorting is an indicator of negative returns to come in the following month. Using shorting's share of volume, the return differences range from $0.97 \%$ to $1.59 \%$ per month across the volatility quintiles. Still, the biggest effects are in the most volatile stocks, with return differences as high as $4.90 \%$ per month.

Lastly, in Table 3 Panel D we examine the predictive power of shorting activity controlling for trading volume. Lee and Swaminathan (2000) find that high-volume firms underperform low-volume firms, which makes it important to rule out the possibility that our shorting activity measures are simply reflecting overall trading activity. And the data do in fact rule out this alternative. Shorting flow strongly explains the cross-section of future returns regardless of the amount of overall turnover. Using shorting's share of trading volume as the second sort variable, return differences average $0.74 \%$ to $1.44 \%$ per month across trading volume quintiles. This establishes that the shorting effect in this paper is independent of the volume regularity identified in Lee and Swaminathan. Again, it is interesting to note that these excess returns are also being earned in the most active stocks. In the most active quintile, the heavy shorting quintile underperforms shorting quintile 1 by as much as $2.12 \%$ per month (based on the number of short trades). As discussed in the double sorts with size, these results are striking, because anomalies in finance tend to be found in less active, illiquid stocks. But it is important to remember that these return differences are not tradable and are simply returns to private information, and there is no requirement that there be less private information about active stocks.

Another concern is whether our shorting measures are collinear with monthly changes in short interest, and whether this accounts for the future return differences. As discussed in the introduction, short interest may have some ability to predict the cross-section of returns,. Certainly our shorting flow measures are correlated with monthly changes in short interest, because they are a component of that monthly change. The monthly change in short interest is

\footnotetext{
${ }^{5}$ In results not reported, we also confirm that our shorting flow measures do not chase out the underperformance of very volatile stocks. In fact, our evidence indicates that these stocks are being shorted on a regular basis, which suggests that short sale constraints cannot easily account for Ang et al.’s return findings.
} 
the sum of shares shorted in our sample over the relevant days plus manual NYSE short sales plus off-NYSE short sales less all covering transactions. The null hypothesis is that the monthly changes in short interest are sufficient to capture the information possessed by short sellers.

To investigate this, we use a double sort method. The first sort is based on monthly short interest changes for the previous month, in shares. The second sort is based on one of the three shorting flow measures for the past five days. As before, the portfolio holding period is 20 days, and we calculate a new set of portfolios and holding period returns for each trading day. The results are in Table 4 Panel A, and they show the difference in value-weighted cumulative 20day Fama-French alphas following heavy vs. light shorting. Short interest does not drive out the shorting flow measures. For instance, using shorting normalized by trading volume, heavily shorted stocks underperform lightly shorted stocks by $0.83 \%$ to $1.99 \%$ per month across the short interest quintiles, with all but one coefficient strongly significant.

Panel B reverses the sorting order. First we sort on our shorting flow measure, and then we sort on changes in short interest and examine future returns on stocks with the biggest increases in short interest vs. the biggest decreases. In all but two cases, the shorting flow measures drive out short interest. That is, once we control for shorting flow, changes in short interest do not seem to predict the future cross-section of returns. This indicates that our measures are a better proxy for the information in short sales.

\section{C Trading by different account types}

We now turn to the question asked in the title of the paper. Recall that we partition into six different account types: individual, institutional (program and non-program), member-firm proprietary (program and non-program), and other. What might we expect going in to the exercise? As noted in the introduction, it is not obvious that individual shorts would be less informed than institutional or member-firm proprietary shorts. It is also hard to know what to expect for program vs. non-program trades. As mentioned earlier, program trades are defined as simultaneous trades in 15 or more stocks worth at least \$1 million. One well-known type of program trade is index arbitrage, which involves trading baskets of stocks when they become slightly cheap or dear relative to index derivatives such as futures. Index arbitrage short positions seem unlikely to contain any information about the cross-section. However, hedge funds and other institutions often use program trades to quickly and cheaply trade a large number 
of names, since the commission rate is often lower for computerized program trades. Such program trades often mix buys and sells together. Clearly, in such cases the hedge funds believe they have private information about the cross-section that is not yet incorporated into price. Our priors about proprietary trades are also fairly diffuse. If these proprietary trading desks are mostly acting as market-makers, they are likely to be uninformed over the longer term about fundamentals. ${ }^{6}$ However, proprietary trading desks often trade like hedge funds, and one might expect those shorts to be more informed.

Table 1 Panel $\mathrm{C}$ helps to provide some sense of the distribution of shorting across account types. Shorting by individuals on the NYSE is fairly rare, as they tend to account for $1 \%$ to $2 \%$ of overall shorting volume. This is not peculiar to shorting; overall NYSE order flow exhibits similar patterns (see, for example, Jones and Lipson (2004)). Part of the explanation is that individuals account for only a small amount of overall trading volume. But part of this paucity of individual orders is due to the brokerage routing decision. Many, if not most, brokerage firms either internalize retail orders in active stocks or route these orders to regional exchanges or third-market dealers in return for payment. As a result, very few orders from individuals make their way to the NYSE. Institutional trades are the most common short sale orders, accounting for about $74 \%$ of the total shares shorted via system orders. Member-firm proprietary shorts represent about $20 \%$ of total shorting. Somewhat surprisingly, if we slice firms by market cap, volatility, or prior return, there is not much variation in these fractions of overall shorting volume.

To investigate the information in short sales by different account types, we begin again with a sorting approach. Each day, stocks are sorted into quintiles based on shorting activity by the specified account type over the previous five days. Instead of reporting results for three different shorting activity measures, from now on we use shorting's share of trading volume, which as discussed earlier is most orthogonal to size, book-to-market, and trading activity variables that have been previously studied. Returns are calculated for each of these five valueweighted portfolios, and the focus continues to be on the daily return difference between the heavy shorting quintile and the light shorting quintile. Cumulative differences in Fama-French

\footnotetext{
${ }^{6}$ Member-firm proprietary desks can supply liquidity without competing directly with the specialist. For example, a block desk may purchase a large block of stock from a customer early in the day (in the upstairs market) and then proceed to gradually trade out of the position on the exchange floor.
} 
alphas are calculated at various horizons up to 20 days. Since a new set of portfolios is formed every day, this results in overlapping return observations, and Newey-West standard errors are used to account for the overlap.

The results are detailed in Table 5, beginning in Panel A. For comparison to earlier results in Table 2, aggregate shorting by all account types is considered first. The heavy shorting quintile underperforms the light shorting quintile by a cumulative $1.07 \%$ over the following 20 trading days, which is more than $14 \%$ annualized, and this underperformance is strongly statistically significant, with a t-statistic of 5.10 .

Next we look at short sales initiated by various account types, with the results also reported in Table 5 Panel A. Institutions and member-firm proprietary short sales that are not part of a program trade are the most informed. At the 20-day mark, stocks with heavy shorting by institutions underperform the light shorting quintile by a significant amount (a cumulative $1.35 \%$, or over $18 \%$ annualized). The corresponding figure for member-firm proprietary nonprogram shorts is $1.07 \%$ or over $14 \%$ annualized, and both return differences are statistically quite different from zero. The non-program institutional and proprietary alphas are not statistically distinguishable from each other, but they are reliably more informed than all other account types. For example, program trades are much less informed than non-program counterparts. Stocks heavily shorted by institutional program trades underperform by just $0.60 \%$ over the next 20 trading days, while proprietary program trades seem to be totally uninformed, since heavy shorting by these account types actually predicts slight outperformance (0.06\%) over the following month. Similarly, we cannot reject the hypothesis that individual shorts are completely uninformed, because the quintile of stocks most heavily shorted by individuals underperforms the light shorting quintile by only $0.27 \%$ over the next month.

Figure 1 shows the daily evolution of these excess returns up to 20 days. Cumulative excess returns tend to flatten slightly at the longer horizons, suggesting that most of the information possessed by short sellers has been impounded into price by the end of the 20-day period. We have also formally looked at holding periods out to 60 days and find that our shorting flow measures have no predictive power beyond the 20-day horizon. The information in short sales seems to be shorter-lived than one month.

Much of the 2000-2004 sample period is characterized by a substantial and extended market decline. One might wonder if the predictive power of shorting flow is most valuable in a 
declining market. Figure 2 addresses this concern, and more generally shows the profits and losses over time from this hypothetical "trading strategy." Specifically, it shows the raw return differences between the heavy shorting and light shorting quintiles for non-overlapping 20-day holding periods, based on shorting relative to trading volume. Considering all shorting activity, heavily shorted stocks underperform lightly shorted stocks in just over $60 \%$ of the months. There are several months where heavy shorts underperform by $3 \%$ to $4 \%$, and there is a single month in 2001 where heavily shorted stocks actually outperform lightly shorted stocks by $8 \%$. When quintiles are assigned using non-program institutional shorting activity, the results are a bit more one-sided. The heavily shorted quintile underperforms the light shorting quintile about $75 \%$ of the time. There are four months during which underperformance exceeds $5 \%$, but there is only one month with outperformance of $5 \%$. The best month for short sellers occurs around the peak of the aggregate market in early 2000 , when underperformance exceeds $10 \%$. These graphs are similar to those for many tradable regularities, with favorable return differentials in many but by no means all months. We also checked formally whether the results were different across calendar years and found no evidence of nonstationarity.

This period was also characterized by a number of high-profile frauds and collapses, including Enron, Worldcom, and Adelphia, among others. Worldcom and Adelphia are not in our sample because they were listed on Nasdaq. But one might worry that the results are being driven by a small number of extreme observations where short sellers made the bulk of their profits. This is not the case; the results are not driven by a small number of outliers. When we exclude firms in the far left tail of the holding period return distribution (the worst $1 \%$ or $5 \%$ ), the magnitudes of underperformance are slightly reduced, but the qualitative results are unchanged. The remaining $95 \%$ or $99 \%$ of stocks continue to underperform if they have been heavily shorted.

An important question is how the information possessed by these short sellers gets into price. One possibility is that the market is looking carefully for evidence of shorting in order to copy their trading behavior. This is consistent with the data in Aitken et al. (1998), where the disclosure of a short sale on the tape in Australia led to an immediate decline in price. The corresponding disclosure in the US is monthly short interest, so one might guess that once short interest is published, prices react to the surprise changes in short interest. To determine whether this accounts for our return differences, we identified the short interest release date each month 
during our sample and excluded it from the portfolio holding period. The results are in Table 5 Panel B, and excluding the short interest release date makes virtually no difference in the measured underperformance of heavily shorted stocks. Whatever the nature of the information possessed by short sellers, the release of short interest does not appear to be an important mechanism for incorporating that information into prices.

Because individuals execute few short sales on the NYSE, as many as $40 \%$ of NYSE stocks experience precisely zero short sales by individuals over a given 5-day period. This large mass at zero makes it difficult to assign stocks to quintiles. In Table 5 Panel $\mathrm{C}$, the portfolio assignment process is adjusted accordingly. We first identify all stocks with zero short sales by individuals during a given five-day portfolio formation period and assign them to portfolio $0 .^{7}$ All remaining stocks are sorted into quintiles 1 through 5 based on shorting relative to volume, and we examine the excess return on portfolio 5 over that of portfolio 0 at various horizons out to 20 days. In calculating the average excess return, we only include holding periods for which portfolio 0 has at least 20 stocks.

The results are modestly different. Twenty days after portfolio formation, stocks that are heavily shorted by individuals underperform stocks that are completely unshorted by a cumulative $0.54 \%$, with a marginally significant t-statistic of 1.95 . This return difference is still well below the $1 \%+$ return differences for institutions and for member-firm proprietary short sales.

All of the above analysis on shorting by different account types has been univariate in nature. Non-program shorting by institutions contains the most information about the crosssection of future stock returns. But shorting by various account types is positively contemporaneously correlated, so an important question is whether short sellers of various account types are acting on similar information. Perhaps there is a common factor describing this shorting behavior, in which case it is enough to look at institutional shorting alone. Alternatively, perhaps other account types are shorting based on orthogonal sources of information about share price. For example, institutions may be trading based on fundamental

\footnotetext{
${ }^{7}$ In principle, we could follow the same approach for short sales by the remaining account types. However, there are many more short sales by these account types, which means there are very few stocks that experience no short selling by a given non-individual account type over a period of five trading days. Thus, we only perform this exercise for short sales by individuals.
} 
information, while member firm proprietary trading desks may be trading based on their knowledge of order flow in a stock. These two signals may or may not be related.

To investigate this, we run cross-sectional predictive regressions including shorting by all four account types, to see if each account type contributes incremental explanatory power for future returns. There is one cross-sectional regression per day, and it uses five days' worth of shorting information. The dependent variable is the next day's return or the return over the next 20 trading days. We use a Fama-MacBeth approach to conduct inference, with Newey-West standard errors to account for overlap when portfolio holding periods are longer than one day.

Panel A of Table 6 looks at the cross-section of returns one day ahead. The univariate regressions confirm that shorting by each account type except proprietary program trades helps explain future returns. When all six account types are put into the regression at the same time, both types of member-firm proprietary shorts become insignificant. Short sales by individuals and other account types also become insignificant using the 20-day holding period. This is somewhat surprising, since proprietary and other account types showed strong univariate predictive power. It suggests that shorting by these account types is correlated with institutional shorting, but the institutional shorting dominates in terms of information content. We have also run these regressions with additional controls, and the results are qualitatively unchanged.

The coefficient estimates are particularly interesting, because they are not similar across account types. At 2.64 in the Panel A multiple regression, the coefficient on individual shorting is bigger in magnitude than the coefficient on any other type of shorting activity, though it is not always statistically larger than the other coefficients. The interpretation is that a given amount of shorting has more predictive power if it comes from an individual than if it comes from an institution. One is tempted to conclude from this that individual short sales are more informative than institutional short sales. But that can be misleading, because the two account types generally trade vastly different quantities. If the question is whether an additional shorted share by an individual or an institution is most informative, then the answer based on the point estimates is that an additional share from an individual is more informative. But if the question is who has the most information about the cross-section, which stocks are overvalued vs. undervalued, then the answer is that institutions are the most informed. 


\section{D. Persistence and cross-persistence of different short sellers}

So far we have ignored the time-series persistence of our shorting measures. The focus has been solely on the cross-section of future returns. Table 1 Panel B gives some hints about how shorting order flow is related to the next day's order flow but does not provide any details about the persistence and cross-persistence of shorting by different account types. For example, it would be interesting to know if institutional shorts obtain their return advantage by trading faster on the same information as individuals, which would manifest itself as institutional shorting predicting future individual shorting. One way to proceed would be to estimate vector autoregressions on short sale flow by various account types, along the lines of Hasbrouck (1991, 1996) or Hendershott and Jones (2005). The problem with this approach is that it should be performed stock by stock, and it becomes difficult to aggregate the results cross-sectionally and conduct inference, since there is almost certainly cross-sectional correlation.

As an alternative, we again opt for an approach along the lines of Fama-MacBeth. We estimate a series of cross-sectional autoregressions, and we then use time-series methods to

conduct inference. Specifically, we estimate the following six cross-sectional regressions on each day $t$ :

$$
x_{i t}^{j}=\alpha_{j}+\beta_{j 1} x_{i, t-1}^{1}+\beta_{j 2} x_{i, t-1}^{2}+\ldots+\beta_{j 6} x_{i, t-1}^{6}+\varepsilon_{i t}^{j},
$$

where $x_{i t}^{j}$ is the $\mathrm{j}^{\text {th }}$ account type's shorting flow for stock $i$ on day $t$. This regression is estimated for each of the six account types as the dependent variable. We average coefficient estimates over time and use Newey-West standard errors to conduct inference.

The results are in Table 7. Note that individual shorting is the least persistent, with an autoregressive coefficient of 0.224 . This is consistent with other results in the microstructure literature, such as Jones and Lipson (2004), that indicate that individual order flow is closer to a random walk than any other type of order flow. Cross-persistence coefficients are harder to interpret, because each account type has a different shorting market share. But it is still straightforward to conduct inference on the null hypothesis of no cross-persistence. To return to the question posed above, we might ask whether institutions lead individuals in non-program shorting. The evidence says yes, but individuals also lead non-program shorting by institutions, as today's individual shorting also predicts tomorrow's institutional shorting. Thus, it does not appear that institutions are uniformly shorting faster than individuals on the same information. 


\section{E. Order size}

Because we can observe individual short sale orders in every NYSE stock, it becomes possible to look at the informativeness of large short sales vs. small short sales. Our prior was that small short sales would be uninformed. In fact, the stealth trading results of Barclay and Warner (1993) and Chakravarty (2001) suggest that medium-sized shorts might be the most informative.

Short sale orders are partitioned into five order size categories: less than 500 shares, 500 to 1,999 shares, 2,000 to 4,999 shares, 5,000 to 9,999 shares, and orders of at least 10,000 shares. Table 8 reports some summary statistics on the prevalence of each order size. Panel A shows that exactly half of executed short sale orders are for less than 500 shares. Not surprisingly, these fractions decline monotonically with order size: $31 \%$ of short sale orders are between 500 and 1,999 shares, $10 \%$ are between 2,000 and 4,999 shares, 5\% are between 5,000 and 9,999 shares, and $4 \%$ are for at least 10,000 shares.

Panel B shows how this mix of order sizes varies across account types. The average institutional short sale order is 550 shares if part of a program trade and 743 shares otherwise. There is an even bigger differential for proprietary trades: the average size is 398 shares for shorts that are part of a program trade, and 729 shares for non-program shorts. Interestingly, both individual and other account type shorts tend to be larger on average. The average individual short is 820 shares, while the average short from the "other" account type is 1,015 shares.

Some researchers partition by trade size and argue that large trades are institutional, while small trades are retail. Panel B shows that, at least for short sales, this is an unwarranted generalization. Institutions account for fully 58\% of NYSE short sale orders that are less than 500 shares, with member firms responsible for another 34\% of these short sales. The message here is that most shorting is non-retail, so it makes sense that shorting at every size is dominated by non-retail orders. It is true that institutions are even more dominant at medium order sizes, accounting for $73 \%$ of the short sale orders between 2,000 and 4,999 shares. But institutional "market share" is not monotonic in order size. For the largest shorts (10,000 shares or more), institutions account for only 53\% of the total. It is worth noting that the "other" account type submits a disproportionate number of large short sale orders. While this account type is 
responsible for only $7 \%$ to $9 \%$ of the orders under 5,000 shares, it accounts for $31 \%$ of the $10,000+$ share orders.

We use a double sort method to investigate large and small short sales separately. Each day, we first sort stocks into quintiles based on shorting activity over the past five days, with shorting activity measured as shorting's fraction of overall trading volume in that stock. Within a quintile, we then sort a second time into quintiles based on the fraction of that stock's short sale orders that are of a given size. The result is a set of stocks with similar overall shorting activity but different shorting activity at a given order size. We repeat this exercise for each of the five order size categories.

For each order size category, value-weighted returns and Fama-French alphas are calculated and reported in Table 9 for 5 x $5=25$ portfolios over the next 20-day holding period. Return differences are then calculated as the return on the second sort's (the fraction of shorts in a given size bucket) top quintile minus the return on the bottom quintile. This number is negative if the quintile where shorting of a given order size is most prevalent underperforms the quintile where shorting of a given order size is least prevalent. These are also reported in Table 9. Because these portfolio holding periods overlap, we conduct inference using Newey-West standard errors with the appropriate number of lags. Return differences are reported for each of the shorting activity quintiles and for each order size bucket.

An example may help here. Suppose we want to investigate the informativeness of small short sales. First sort stocks based on shorting's share of trading volume over the past five days, and consider for example the lowest quintile, which consist of lightly shorted stocks. For each stock in this quintile, calculate the fraction of its short sale orders that are for less than 500 shares (lon1 in the Table). Sort a second time into quintiles based on this small order fraction. Now calculate value-weighted returns over the next 20 days for the sub-quintile with the most small short sale orders vs. the sub-quintile with the fewest small short sale orders. The return difference is the quintile with the most orders of a given size minus the quintile with the least orders of a given size. In our example, Table 9 gives the Fama-French alpha on this return difference as $0.70 \%$. That is, among stocks with the least overall shorting activity, stocks with many small short sale orders outperform stocks with few small short sale orders by $0.70 \%$ over the next month. 
This result is quite striking, because small short sales are worse than uninformed. In fact, they seem to appear at exactly the wrong times. One shouldn't follow these small shorts at all. If one could identify and instead buy the stocks where shorting is dominated by small orders, these would outperform stocks where small short sales are less prevalent. In fact, this result holds across this entire row of the Table regardless of overall shorting activity, with 20-day returns between $0.47 \%$ and $0.96 \%$.

In contrast, when large short sale orders dominate the mix, stocks tend to underperform. When short sales between 2,000 and 5,000 shares are most prevalent (high values of lon3), stocks tend to underperform by $0.65 \%$ to $0.90 \%$ over the next 20 days. The numbers are even more dramatic for the biggest short sale orders. When orders to short at least 10,000 shares are most prevalent, the stock underperforms by an average of $1.03 \%$ to $1.66 \%$ in the following month. This indicates that these particular short sellers are better informed about future stock price moves. Again, none of these results seem to change moving horizontally across Table 9. This indicates that the same pattern holds across groups with different aggregate shorting activities.

Interestingly, these results do not quite match earlier stealth trading results, which are calculated using all buys and sells rather than just short sales. The results on small short sales are similar: they appear to be completely uninformed. The stealth trading results would suggest that medium-sized shorts contain the most information. But we find that the information in short sales is monotonic in order size. The larger the short sale, the more informative it is about future price moves. In contrast to the stealth trading results, the biggest short sales of over 10,000 shares appear to have the biggest ability to predict future price moves.

While we are not sure why this is so, one possibility is that these short sellers possess short-term information and cannot afford to be patient in executing their orders. Another possible explanation is that the uptick rule might inhibit the kind of slicing and dicing that we see on many other institutional orders. If the uptick rule reduces the probability of getting an order executed, perhaps short sellers cannot afford the execution uncertainty associated with splitting orders and submit large orders instead. If this second explanation is true, we might see this result change for those stocks that become exempt from the uptick rule during the 2005 pilot program. 


\section{Further robustness checks}

Up to now, we have mostly controlled for one alternative explanation at a time. Here we use a Fama-MacBeth regression approach to include multiple characteristic controls. For each trading day $t$, we run a cross-sectional regression of the $[t, t+20]$ risk-adjusted stock return on the $[t-4, t]$ shorting activity measure as well as time $t$ controls. We risk-adjust using the FamaFrench 3-factor model. Here we use daily data for each stock for the previous calendar quarter to estimate a time-series regression of returns on Fama-French factors in order to obtain factor loadings, and we apply these factor loadings for each stock to the daily factor returns during the holding period in order to calculate each stock's holding period alpha. The portfolio alpha is just the value-weighted average of the component alphas. Shorting as a fraction of trading volume is used as the measure of shorting flow, since this is the most orthogonal to other firm characteristics such as size and trading volume.

Table 8 provides some summary statistics on the controls used here. We include log size, the book-to-market ratio, the previous week's return on a given stock as a measure of short-term momentum, individual daily stock return volatility over the previous month, the effective spread on the stock as a measure of its liquidity, turnover as a measure of trading activity, and the fraction of short sales that are executed using marketable orders (omkt), which as a measure of trading impatience could reflect the presence of more information or more short-lived information. Panel A reveals that on average, about $42 \%$ of short sales are executed via market orders or marketable limit orders, though there is considerable variation in that fraction across days and across stocks. We also include measures of the prevalence of certain order sizes. For each stock, lon1- lon5 are the fraction of the number of shorting orders with order size smaller than 500 shares, between 500 and 1,999 shares, between 2,000 and 4,999 shares, between 5,000 and 9,999 shares, and at least 10,000 shares respectively.

In Panel C, the most interesting correlation is between the shorting measure and the prior week's return. Our shorting measure is also being calculated over the past five days, so these two variables are exactly contemporaneous, and except for individual accounts the correlations are positive and economically significant, at 0.20 using all short sales. Diether, Lee, and Werner (2005) provide similar evidence for Nasdaq firms, indicating that short sellers are not driving down the price as they trade but are instead shorting more as the stock price rises. Perhaps this is 
just a consequence of the uptick rule, but it indicates that shorting pressure itself is not driving down stock prices.

For completeness, Panel D reports the correlations between the various characteristics. Since these characteristics will be used as controls in a regression framework, it is important to identify any multicollinearity that might be present. There are modest and unsurprising correlations between market cap, book-to-market, volatility, and turnover. Also not surprising is the negative correlation between the prevalence of small short sales and larger short sales, since these are constrained to add to one. Slightly more interesting are the correlations between short sale order size and market cap, or order size and effective spread. Small stocks tend to have more small short sales $(\rho=-0.31)$, and stocks with wide spreads tend to have more small short sales $(\rho=0.25)$.

The results of the Fama-MacBeth regressions with controls are in Table 10. There is a separate regression for each account type's shorting activity, each with all of the controls. For almost all of the account types, shorting significantly explains the cross-section of returns over the next 20 days. The one exception is program shorts submitted by institutions, which has become indistinguishable from zero. Most of the controls are insignificant. The exceptions are size, book-to-market, and sometimes the prior 5-day return and the prevalence of marketable vs. limit orders to sell short. Small firms seem to earn higher Fama-French alphas during this sample, as do low book-to-market firms, which is somewhat surprising. We have also looked at shorter horizons of 1 to 15 days as well as subsets of these controls, and the results are virtually identical.

\section{Discussion}

Before the reader begins to raise money for a hedge fund trading on these return differentials, it is important to emphasize again that these shorting flow measures are not publicly observable, which means that these excess returns are not achievable. Instead, these return differences should be viewed as indications of the returns to private information possessed by shorts in aggregate. They are indications because we do not observe the entire trading history of short-sellers. We would be able to calculate exact excess returns to a class of short sellers only if we knew all of the shorts and all of the covering trades. As it stands, the returns reported 
here are the gross returns available to a hypothetical bystander who observes system shorting flow in all stocks.

As discussed earlier, some market participants may be able to see pieces of this flow. The NYSE specialist can observe the short-selling system order flow, though only in the small number of stocks that he trades. The specialist may have some ability to shade his trading accordingly, but the market-making requirements for specialists probably limit the ability to profit from this information. Brokerage firms obviously observe the part of the shorting flow that they handle, and they could use that information to copy their customers' shorts if they believe that their customers are informed. But the complete flow data for this sample period are observable only to the econometrician.

We also want to reiterate that all of the returns reported here are gross returns, because frictions are completely ignored. Even if a market participant could observe the short sale flow information, she might not be able to locate shares to borrow for shorting, and even if she could locate shares, borrowing those shares might be expensive. Both of these would reduce her returns. However, aggregated across a broad portfolio of stocks, the pecuniary cost of borrowing shares is generally not too large. Only a small number of individual stocks carry negative rebate rates, and based on other researchers' reported summary statistics, a broad portfolio of stocks might cost $1 \%$ per year to short, which is far lower than the magnitude of the excess returns to private information reported here. Of course, lending fees would be increasing in the amount borrowed, so there could be scale limits for any trader making use of these shorting flow data.

We have also ignored run-of-the-mill trading costs. The implicit trading strategies considered here involve the potential for substantial turnover on a daily basis (though the timeseries evidence in Table 7 indicates that shorting is strongly autocorrelated even within-firm, and since portfolios here are based on the cross-section of shorting, any fixed effect across firms would further reduce the required turnover). The resulting trading costs could be significant, especially if trading is conducted in small, less liquid stocks. There is one mitigating factor: the uptick rule implicitly forces short sellers to be less aggressive in demanding liquidity, which reduces realized trading costs. However, the uptick rule may increase opportunity costs for short positions that end up not being taken or are initiated with a delay.

Finally, we are interested in understanding more about the source of the underperformance in heavily shorted stocks. There is some evidence that short sellers possess 
information about fundamentals. For example, Christophe, Ferri, and Angel (2004) find that negative earnings surprises are preceded by abnormal short selling. Francis, Venkatachalam, and Zhang (2005) show that short sellers are able to predict downward analyst forecast revisions, while Desai, Krishnamurthy, and Venkataraman (2005) find that short sellers are able to anticipate earnings restatements. However, Daske, Richardson, and Tuna (2005) do not find that short sellers anticipate negative earnings shocks. We think this is a promising area of research.

\section{Conclusion}

In this paper, we use proprietary system order data from the New York Stock Exchange to examine the incidence and information content of all short sales and various subsets. There are two striking results. First, short selling is quite common. Shorting accounts for $12.9 \%$ of trading volume on average.

The second and main result is that these short sellers are extremely well-informed. We quantify this information content in a number of different ways. Perhaps the simplest is a portfolio sorted into quintiles based on one day's shorting activity. Over the next 20 trading days, a value-weighted portfolio of heavily shorted stocks underperforms lightly shorted stocks by a cumulative $1.07 \%$ on average (over $14 \%$ on an annualized basis). Of the six account types present in the data - individual, institutional (program and non-program), member-firm proprietary (program and non-program), and other - non-program institutional shorts are the most informed. Compared to stocks that are lightly shorted by institutions, the quintile of stocks most heavily shorted by institutions in a given week underperforms by $1.35 \%$ over the next 20 trading days (more than 18\% on an annualized basis). These alphas do not account for the cost of shorting, and they cannot be achieved by outsiders, because the internal NYSE data that we use are not generally available to market participants. But these gross excess returns to shorting indicate that institutional short sellers have identified and acted on important value-relevant information that has not yet been impounded into price. The results are strongly consistent with the emerging consensus in financial economics that short sellers possess important information, and that their trades are important contributors to more efficient stock prices. 


\section{References}

Aitken, M., Frino, A., McCorry, M., Swan, P., 1998, Short sales are almost instantaneously bad news: evidence from the Australian Stock Exchange, Journal of Finance 53, 2205-2223.

Ang, Andrew, Robert Hodrick, Yuhang Xing, and Xiaoyan Zhang, 2005, The cross-section of volatility and expected returns, Journal of Finance, forthcoming.

Asquith, Paul and Lisa Meulbroek, 1996, An empirical investigation of short interest, working paper, Harvard University.

Asquith, Paul, Parag Pathak, and J. R. Ritter, 2004, Short interest, institutional ownership, and stock returns, Journal of Financial Economics, forthcoming.

Barclay, Michael J. and Jerold B. Warner, 1993, Stealth trading and volatility: Which trades move prices? Journal of Financial Economics 34, 281-305.

Boehmer, Ekkehart and Eric Kelley, 2005, Institutional investors and the informational efficiency of prices, working paper, Texas A\&M University.

Brent, Averil, Dale Morse, and E. Kay Stice, 1990, Short interest - explanations and tests, Journal of Financial and Quantitative Analysis 25, 273-289.

Chakravarty, Sugato, 2001, Stealth-trading: Which traders' trades move stock prices? Journal of Financial Economics 61, 289-307.

Christophe, Stephen E., Michael G. Ferri, and James J. Angel, 2004, Short-selling prior to earnings announcements, Journal of Finance 59, 1845-1876.

Cohen, Lauren, Karl Diether, and Christopher Malloy, 2005, Supply and demand shifts in the shorting market, working paper, University of Chicago.

Daniel, K., Grinblatt, M., Titman, S., Wermers, R., 1997. Measuring mutual fund performance with characteristic-based benchmarks. Journal of Finance 52, 1035-1058.

Daske, Holger, Scott A. Richardson, and A. Irem Tuna, 2005, Do short sale transactions precede bad news events?, working paper, University of Pennsylvania.

D’Avolio, Gene, 2002, The market for borrowing stock, Journal of Financial Economics 66, 271306.

Dechow, P., Hutton, A., Meulbroek, L., Sloan, R., 2001, Short-sellers, fundamental analysis, and stock returns. Journal of Financial Economics 61, 77-106. 
Desai, Hemang, Srinivasan Krishnamurthy, and Kumar Venkataraman, 2005, Do short sellers target firms with poor earnings quality? Evidence from earnings restatements, Review of Accounting Studies, forthcoming.

Desai, H., K. Ramesh, S.R. Thiagarajan, and B.V. Balachandran, 2001, An investigation of the informational role of short interest in the Nasdaq market, Journal of Finance,

Diether, Karl, Kuan-Hui Lee, and Ingrid Werner, 2005, Can short sellers predict returns? Daily evidence, working paper, Ohio State University.

Evans, Richard B., Christopher C. Geczy, David K. Musto, and Adam V. Reed, 2003, Failure is an option: impediments to short-selling and option prices, working paper, University of Pennsylvania.

Fama, Eugene F. and Kenneth R. French, 1993, Common risk factors in the returns on stocks and bonds, Journal of Financial Economics 33, 3-56.

Francis, Jennifer, Mohan Venkatachalam, and Yun Zhang (2005), Do short sellers convey information about changes in fundamentals or risk?, working paper, Duke University.

Geczy, Christopher C., David K. Musto, and Adam V. Reed, 2002, Stocks are special too: an analysis of the equity lending market, Journal of Financial Economics 66, 241-269.

Griffin, John M., Jeffrey H. Harris, and Selim Topaloglu, 2003, The dynamics of institutional and individual trading, Journal of Finance, forthcoming.

Harrison, J. Michael and David M. Kreps, 1978, Speculative investor behavior in a stock market with heterogeneous expectations, Quarterly Journal of Economics, 323-336.

Hasbrouck, Joel, 1991, Measuring the information content of stock trades, Journal of Finance 46, 179-207.

Hasbrouck, Joel, 1995, One security, many markets: Determining the contributions to price discovery, Journal of Finance 50, 1175-1199.

Hasbrouck, Joel, 1996, Order characteristics and stock price evolution: an application to program trading, Journal of Financial Economics 41, 129-149.

Hendershott, Terrence and Charles M. Jones, 2005, Island goes dark: transparency, fragmentation, and regulation, Review of Financial Studies, forthcoming.

Jones, Charles M., 2004, Shorting restrictions, liquidity, and returns, Columbia University working paper.

Jones, Charles M. and Owen A. Lamont, 2002, Short sale constraints and stock returns, Journal of Financial Economics, 66, 207-239. 
Jones, Charles M., and Marc L. Lipson, 2004, Are retail orders different?, Columbia University working paper.

Kaniel, R., Gideon Saar, and Sheridan Titman, 2005, Individual investor sentiment and stock returns, working paper, New York University.

Lee, Charles M.C. and Bhaskaran Swaminathan, 2000, Price momentum and trading volume, Journal of Finance 55, 2017-2069.

Lamont, Owen A. and Richard H. Thaler, 2003, Can the market add and subtract? Mispricing in tech stock carve-outs, Journal of Political Economy 111, 227-268.

Lamont, Owen A. and Jeremy C. Stein, 2004, Aggregate short interest and market valuations, American Economic Review.

Loughran, T., and Jay R. Ritter, 2004, Why has IPO underpricing increased over time?, Financial Management 33, 5-37.

Miller, E.M., 1977, Risk, uncertainty, and divergence of opinion, Journal of Finance 32, 11511168.

Ofek, Eli and Matthew Richardson, 2003, DotCom mania: a survey of market efficiency in the internet sector, Journal of Finance 58, 1113-1138.

Ofek, Eli, Matthew Richardson, and Robert Whitelaw, 2004, Limited arbitrage and short sales restrictions: evidence from the options markets, Journal of Financial Economics. 


\section{Table 1. Summary statistics}

The sample consists of all common stocks listed on the NYSE and extends from January 2000 through April 2004. Shorting turnover is defined as shares sold short on a given day as a percentage of shares outstanding in that stock. Shorting share of volume is shares sold short on a given day as a percentage of NYSE trading volume in that stock on that day. All shorting is aggregated per stock per day; reported figures are time-series averages of cross-sectional statistics. Correlations different from zero at $\mathrm{p}=5 \%$ are given in bold in Panel B.

Panel A: Daily system shorting per stock

\begin{tabular}{cccc}
\hline & $\begin{array}{c}\text { Number of } \\
\text { shorting trades } \\
\text { (trades) }\end{array}$ & $\begin{array}{c}\text { Shares sold } \\
\text { short } \\
\text { (shares) }\end{array}$ & $\begin{array}{c}\text { Shorting share } \\
\text { of volume } \\
\text { (sfrac) }\end{array}$ \\
\hline Mean & 146 & 99,747 & $12.86 \%$ \\
Cross-sectional Std Dev & 194 & 232,541 & $10.59 \%$ \\
$25 \%$ & 23 & 6,331 & $4.90 \%$ \\
$50 \%$ & 77 & 27,425 & $10.27 \%$ \\
$75 \%$ & 192 & 95,417 & $18.10 \%$ \\
Avg. number of stocks & 1,239 & 1,239 & 1,239 \\
\hline
\end{tabular}

Panel B: Correlations and autocorrelations between returns and system shorting measures

\begin{tabular}{cccccccc}
\hline & trades $_{\mathrm{t}}$ & shares $_{\mathrm{t}}$ & sfrac $_{\mathrm{t}}$ & ret $_{\mathrm{t}-1}$ & trades $_{\mathrm{t}-1}$ & shares $_{\mathrm{t}-1}$ & sfrac $_{\mathrm{t}-1}$ \\
\hline ret $_{\mathrm{t}}$ & $\mathbf{0 . 0 6}$ & $\mathbf{0 . 0 6}$ & $\mathbf{0 . 1 0}$ & $\mathbf{0 . 0 1}$ & $\mathbf{- 0 . 0 1}$ & $\mathbf{- 0 . 0 1}$ & $\mathbf{- 0 . 0 2}$ \\
trades $_{\mathrm{t}}$ & & $\mathbf{0 . 7 1}$ & $\mathbf{0 . 3 4}$ & $\mathbf{0 . 0 5}$ & $\mathbf{0 . 8 4}$ & $\mathbf{0 . 6 0}$ & $\mathbf{0 . 2 5}$ \\
shares $_{\mathrm{t}}$ & & & $\mathbf{0 . 2 0}$ & $\mathbf{0 . 0 3}$ & $\mathbf{0 . 5 9}$ & $\mathbf{0 . 7 5}$ & $\mathbf{0 . 1 1}$ \\
sfrac $_{\mathrm{t}}$ & & & & $\mathbf{0 . 0 9}$ & $\mathbf{0 . 2 4}$ & $\mathbf{0 . 1 1}$ & $\mathbf{0 . 5 2}$ \\
\hline
\end{tabular}

Panel C: System shorting by account type

\begin{tabular}{|c|c|c|c|c|c|c|c|}
\hline & \multirow{3}{*}{$\begin{array}{c}\text { Daily average } \\
\text { shares shorted } \\
\text { per stock }\end{array}$} & \multicolumn{6}{|c|}{ Fraction of total shorting volume } \\
\hline & & \multirow{2}{*}{ Individual } & \multicolumn{2}{|c|}{ Institution } & \multicolumn{2}{|c|}{ Proprietary } & \multirow[t]{2}{*}{ Other } \\
\hline & & & Non-prog. & Program & Non-prog. & Program & \\
\hline \multicolumn{8}{|c|}{ Market Value of Equity } \\
\hline Small & 17,158 & $1.9 \%$ & $60.3 \%$ & $14.0 \%$ & $8.9 \%$ & $9.8 \%$ & $5.1 \%$ \\
\hline Medium & 56,306 & $1.2 \%$ & $57.3 \%$ & $16.9 \%$ & $9.5 \%$ & $10.6 \%$ & $4.6 \%$ \\
\hline Big & 230,125 & $1.4 \%$ & $58.5 \%$ & $14.2 \%$ & $12.8 \%$ & $7.1 \%$ & $5.9 \%$ \\
\hline \multicolumn{8}{|c|}{ Stock Return Volatility } \\
\hline Low & 87,228 & $1.2 \%$ & $56.5 \%$ & $17.7 \%$ & $11.5 \%$ & $7.3 \%$ & $5.7 \%$ \\
\hline Medium & 97,248 & $1.4 \%$ & $57.1 \%$ & $16.0 \%$ & $12.1 \%$ & $7.9 \%$ & $5.5 \%$ \\
\hline High & 105,834 & $1.8 \%$ & $59.4 \%$ & $12.2 \%$ & $12.7 \%$ & $7.7 \%$ & $6.2 \%$ \\
\hline \multicolumn{8}{|c|}{ Past Week Return } \\
\hline Low & 95,421 & $1.6 \%$ & $60.6 \%$ & $13.0 \%$ & $12.2 \%$ & $6.9 \%$ & $5.7 \%$ \\
\hline Medium & 89,497 & $1.2 \%$ & $57.7 \%$ & $16.2 \%$ & $11.6 \%$ & $7.8 \%$ & $5.5 \%$ \\
\hline High & 119,308 & $1.3 \%$ & $57.3 \%$ & $14.9 \%$ & $12.1 \%$ & $8.9 \%$ & $5.5 \%$ \\
\hline
\end{tabular}


Panel D: 25 size and BM portfolios short-selling measures

\begin{tabular}{c|ccccc}
\hline \multicolumn{5}{c|}{ size } \\
BM & small & 2 & 3 & 4 & big \\
\hline \multicolumn{2}{c}{$\begin{array}{c}\text { Daily shares sold short } \\
\text { low }\end{array} 116,722$} & 33,722 & 55,648 & 115,378 & 341,726 \\
2 & 16,201 & 28,523 & 49,568 & 114,064 & 341,813 \\
3 & 12,065 & 23,143 & 55,611 & 111,969 & 293,845 \\
4 & 10,413 & 23,455 & 56,070 & 121,150 & 265,750 \\
high & 14,779 & 39,875 & 94,559 & 171,220 & 336,642 \\
\hline \multicolumn{7}{l}{ Shorting’s share of trading volume } & & & \\
low & $11.6 \%$ & $14.0 \%$ & $15.1 \%$ & $15.2 \%$ & $12.7 \%$ \\
2 & $11.8 \%$ & $14.3 \%$ & $15.2 \%$ & $15.0 \%$ & $13.0 \%$ \\
3 & $11.4 \%$ & $13.6 \%$ & $15.1 \%$ & $15.1 \%$ & $13.6 \%$ \\
4 & $10.7 \%$ & $13.4 \%$ & $14.9 \%$ & $15.1 \%$ & $14.5 \%$ \\
high & $10.5 \%$ & $14.0 \%$ & $15.1 \%$ & $14.5 \%$ & $13.3 \%$ \\
\hline
\end{tabular}




\section{Table 2. Portfolios based on recent system shorting}

The sample consists of all common stocks listed on the NYSE and extends from January 2000 through April 2004. Firms are sorted into quintiles based on the short-selling activity measure for the past five days. Average value-weighted return differences are reported for holding the portfolio for the next 20 days. T-tests are based on Newey-West standard errors.

Panel A. All firms

\begin{tabular}{|c|c|c|c|c|c|c|c|c|c|c|c|}
\hline & $\begin{array}{l}\text { daily } \\
\text { short } \\
\text { orders }\end{array}$ & $\begin{array}{c}\text { daily } \\
\text { shares } \\
\text { shorted }\end{array}$ & $\begin{array}{l}\text { shorting } \\
\text { share of } \\
\text { volume }\end{array}$ & $\begin{array}{c}\text { daily } \\
\text { turnover }\end{array}$ & $\begin{array}{l}\text { daily } \\
\text { ret. } \sigma \\
\text { (ann’d.) }\end{array}$ & $\begin{array}{c}\text { market } \\
\text { cap. } \\
\text { (\$millions) }\end{array}$ & book/mkt & $\begin{array}{l}\text { value- } \\
\text { weighted } \\
\text { return }\end{array}$ & $\begin{array}{c}\text { pf5-pf1 } \\
\text { (t-stat) }\end{array}$ & $\begin{array}{c}\text { Fama } \\
\text { French } \\
\text { alpha }\end{array}$ & $\begin{array}{c}\text { pf5-pf1 } \\
\text { (t-stat) }\end{array}$ \\
\hline \multicolumn{12}{|c|}{ Portfolios sorted by number of executed short sale orders } \\
\hline 1 (least) & 4 & 10,069 & $9 \%$ & $0.40 \%$ & $34.7 \%$ & 1149 & 0.82 & 2.79 & & 2.08 & \\
\hline 2 & 12 & 27,100 & $13 \%$ & $0.50 \%$ & $33.4 \%$ & 1968 & 0.75 & 1.74 & & 1.17 & \\
\hline 3 & 22 & 56,583 & $15 \%$ & $0.58 \%$ & $32.7 \%$ & 3629 & 0.71 & 1.39 & & 0.86 & \\
\hline 4 & 40 & 120,129 & $16 \%$ & $0.62 \%$ & $31.9 \%$ & 7976 & 0.65 & 0.87 & -2.77 & 0.50 & -1.91 \\
\hline 5 (most) & 93 & 391,415 & $16 \%$ & $0.64 \%$ & $32.2 \%$ & 33180 & 0.52 & 0.02 & -9.06 & 0.17 & -8.53 \\
\hline \multicolumn{12}{|c|}{ Portfolios sorted by number of shares shorted } \\
\hline 1 (least) & 5 & 7,337 & $9 \%$ & $0.37 \%$ & $31.7 \%$ & 1163 & 0.77 & 2.60 & & 1.95 & \\
\hline 2 & 13 & 22,697 & $13 \%$ & $0.50 \%$ & $32.6 \%$ & 2006 & 0.73 & 1.61 & & 1.02 & \\
\hline 3 & 24 & 49,997 & $15 \%$ & $0.58 \%$ & $32.6 \%$ & 3720 & 0.68 & 1.27 & & 0.73 & \\
\hline 4 & 41 & 109,811 & $16 \%$ & $0.64 \%$ & $32.8 \%$ & 7764 & 0.66 & 0.94 & -2.57 & 0.55 & -1.77 \\
\hline 5 (most) & 89 & 415,449 & $16 \%$ & $0.65 \%$ & $35.3 \%$ & 33245 & 0.60 & 0.03 & -8.18 & 0.19 & -7.86 \\
\hline \multicolumn{12}{|c|}{ Portfolios sorted by number of shorting's share of volume } \\
\hline 1 (least) & 16 & 59,208 & $5 \%$ & $0.50 \%$ & $35.3 \%$ & 10162 & 0.75 & 1.20 & & 1.28 & \\
\hline 2 & 29 & 110,100 & $9 \%$ & $0.53 \%$ & $33.3 \%$ & 13091 & 0.67 & 0.38 & & 0.44 & \\
\hline 3 & 37 & 137,824 & $13 \%$ & $0.55 \%$ & $32.6 \%$ & 11848 & 0.66 & -0.07 & & -0.09 & \\
\hline 4 & 43 & 147,462 & $17 \%$ & $0.58 \%$ & $32.2 \%$ & 8417 & 0.67 & 0.19 & -0.55 & -0.01 & -1.07 \\
\hline 5 (most) & 46 & 152,020 & $25 \%$ & $0.59 \%$ & $32.2 \%$ & 4539 & 0.69 & 0.66 & -2.21 & 0.21 & -5.10 \\
\hline
\end{tabular}


Panel B: Technology vs. non-tech firms

\begin{tabular}{|c|c|c|c|c|c|c|c|c|}
\hline & \multicolumn{4}{|c|}{ NON-TECH FIRMS } & \multicolumn{4}{|c|}{ TECH FIRMS } \\
\hline & $\begin{array}{c}\text { value- } \\
\text { weighted } \\
\text { return } \\
\end{array}$ & $\begin{array}{c}\text { pf5-pf1 } \\
\text { (t-stat) }\end{array}$ & $\begin{array}{c}\text { Fama } \\
\text { French } \\
\text { alpha }\end{array}$ & $\begin{array}{l}\text { pf5-pf1 } \\
\text { (t-stat) }\end{array}$ & $\begin{array}{c}\text { value- } \\
\text { weighted } \\
\text { return } \\
\end{array}$ & $\begin{array}{l}\text { pf5-pf1 } \\
\text { (t-stat) }\end{array}$ & $\begin{array}{c}\text { Fama } \\
\text { French } \\
\text { alpha }\end{array}$ & $\begin{array}{c}\text { pf5-pf1 } \\
\text { (t-stat) }\end{array}$ \\
\hline \multicolumn{9}{|c|}{ Portfolios sorted by number of shorting trades } \\
\hline 1 (least) & 2.52 & & 2.00 & & 2.69 & & 2.86 & \\
\hline 2 & 1.53 & & 1.11 & & 1.27 & & 1.49 & \\
\hline 3 & 1.23 & & 0.86 & & 0.48 & & 0.64 & \\
\hline 4 & 0.77 & -2.45 & 0.57 & -1.69 & -0.37 & -4.10 & 0.00 & -3.23 \\
\hline 5 (most) & 0.07 & -8.53 & 0.31 & -7.48 & -1.41 & -8.32 & -0.37 & -6.01 \\
\hline \multicolumn{9}{|c|}{ Portfolios sorted by number of shares shorted } \\
\hline 1 (least) & 2.34 & & 1.89 & & 2.57 & & 2.53 & \\
\hline 2 & 1.39 & & 0.98 & & 0.96 & & 1.16 & \\
\hline 3 & 1.16 & & 0.81 & & 0.08 & & 0.21 & \\
\hline 4 & 0.84 & -2.26 & 0.63 & -1.58 & -0.17 & -3.99 & 0.37 & -2.90 \\
\hline 5 (most) & 0.08 & -8.37 & 0.31 & -7.38 & -1.41 & -6.32 & -0.37 & -4.86 \\
\hline \multicolumn{9}{|c|}{ Portfolios sorted by shorting's share of trading volume } \\
\hline 1 (least) & 1.32 & & 1.43 & & -0.07 & & 0.65 & \\
\hline 2 & 0.46 & & 0.61 & & -0.75 & & -0.12 & \\
\hline 3 & -0.10 & & -0.04 & & -1.14 & & -0.43 & \\
\hline 4 & 0.05 & -0.85 & -0.01 & -1.24 & -0.89 & -0.44 & -0.01 & -0.70 \\
\hline 5 & 0.48 & -3.64 & 0.19 & -6.75 & -0.51 & -0.70 & -0.06 & -1.10 \\
\hline
\end{tabular}




\section{Table 3. Return differences on short-sale portfolios after controlling for characteristics}

The sample consists of all common stocks listed on the NYSE and extends from January 2000 through April 2004. Firms are first sorted into quintiles based on the given characteristic for the previous month. Within each quintile, firms are then sorted into quintiles based on the short-selling measure for the past five days. Fama-French alphas for average value-weighted return differences are reported for holding the portfolio for the next 20 days. T-tests are based on Newey-West standard errors.

\begin{tabular}{|c|c|c|c|c|c|c|c|c|c|c|}
\hline & \multicolumn{5}{|c|}{ Panel A: First sort is market capitalization } & \multicolumn{5}{|c|}{ Panel B: First sort is book/market } \\
\hline & low & 2 & 3 & 4 & high & low & 2 & 3 & 4 & high \\
\hline \multicolumn{11}{|c|}{ Second sort: number of shorting trades } \\
\hline pf5 - pf1 & -3.19 & -1.59 & -0.81 & -0.92 & -0.89 & -1.51 & -1.14 & -1.59 & -1.75 & -2.97 \\
\hline t-stat & -9.20 & -4.15 & -2.47 & -3.38 & -4.42 & -5.79 & -2.56 & -3.21 & -5.07 & -7.41 \\
\hline \multicolumn{11}{|c|}{ Second sort: shares sold short } \\
\hline pf5 - pf1 & -2.23 & -1.76 & -0.65 & -1.09 & -0.65 & -1.36 & -1.22 & -1.58 & -1.86 & -2.31 \\
\hline t-stat & -4.71 & -4.00 & -1.44 & -2.93 & -2.68 & -5.51 & -2.63 & -3.15 & -4.90 & -4.59 \\
\hline \multicolumn{11}{|c|}{ Second sort: shorting's share of trading volume } \\
\hline pf5 - pf1 & -3.29 & -1.81 & -1.77 & -1.09 & -1.01 & -0.89 & -1.61 & -1.05 & -1.05 & -1.34 \\
\hline \multirow[t]{3}{*}{ t-stat } & -9.05 & -6.35 & -6.48 & -4.13 & -4.03 & -2.39 & -3.15 & -3.48 & -2.40 & -2.86 \\
\hline & \multicolumn{5}{|c|}{ Panel C: First sort is return volatility } & \multicolumn{5}{|c|}{ Panel D: First sort is share turnover } \\
\hline & low & 2 & 3 & 4 & high & low & 2 & 3 & 4 & high \\
\hline \multicolumn{11}{|c|}{ Second sort: number of shorting trades } \\
\hline pf5 - pf1 & -0.82 & -1.48 & -1.49 & -2.32 & -4.90 & -2.39 & -2.33 & -1.42 & -2.54 & -2.12 \\
\hline t-stat & -2.77 & -5.77 & -3.84 & -4.43 & -6.71 & -6.53 & -7.71 & -4.04 & -5.94 & -4.23 \\
\hline \multicolumn{11}{|c|}{ Second sort: shares sold short } \\
\hline pf5 - pf1 & -0.94 & -1.49 & -1.38 & -2.12 & -4.25 & -2.15 & -1.98 & -1.34 & -2.42 & -2.03 \\
\hline t-stat & -3.26 & -5.90 & -3.62 & -4.54 & -6.10 & -6.13 & -6.49 & -4.14 & -5.74 & -4.14 \\
\hline \multicolumn{11}{|c|}{ Second sort: shorting's share of trading volume } \\
\hline pf5 - pf1 & -0.97 & -1.37 & -1.33 & -1.35 & -1.59 & -1.44 & -1.18 & -0.74 & -0.82 & -1.01 \\
\hline t-stat & -3.53 & -2.96 & -3.48 & -2.69 & -2.75 & -4.56 & -3.96 & -1.61 & -2.22 & -1.94 \\
\hline
\end{tabular}




\section{Table 4. Return differences on short-sale portfolios after controlling for short interest}

The sample consists of all common stocks listed on the NYSE and extends from January 2000 through April 2004. In Panel A, firms are first sorted into quintiles based on changes in short interest for the previous month. Within each quintile, firms are then sorted into quintiles based on the short-selling trading measure for the past five days. In Panel B, we reverse the sorting order. Fama-French alphas for average value-weighted return differences are reported for holding the portfolio for the next 20 days. Ttests are based on Newey-West standard errors. Shorting turnover is shares sold short as a percentage of shares outstanding.

\begin{tabular}{|c|c|c|c|c|c|c|c|c|c|c|}
\hline & \multicolumn{5}{|c|}{$\begin{array}{l}\text { Panel A: First sort is changes in short interest, } \\
\text { second sort is short-selling trade measure }\end{array}$} & \multicolumn{5}{|c|}{$\begin{array}{l}\text { Panel B: First sort is short-selling trade measure, } \\
\text { second sort is change in short interest }\end{array}$} \\
\hline & low & 2 & 3 & 4 & high & low & 2 & 3 & 4 & high \\
\hline \multicolumn{6}{|c|}{ Second sort: number of shorting trades } & \multicolumn{5}{|c|}{ First sort: number of shorting trades } \\
\hline pf5 - pf1 & -2.09 & -1.52 & -2.43 & -1.22 & -1.92 & -0.19 & -0.04 & -1.01 & -0.04 & 0.20 \\
\hline t-stat & -3.99 & -3.25 & -4.37 & -3.48 & -4.52 & -0.53 & -0.17 & -1.98 & -0.09 & 0.40 \\
\hline \multicolumn{6}{|c|}{ Second sort: shares sold short } & \multicolumn{5}{|c|}{ First sort: shares sold short } \\
\hline pf5 - pf1 & -1.97 & -1.66 & -1.95 & -0.81 & -1.18 & -0.90 & -0.55 & -0.37 & 0.11 & 0.10 \\
\hline t-stat & -4.10 & -3.49 & -3.15 & -2.29 & -2.86 & -2.94 & -1.72 & -0.89 & 0.30 & 0.21 \\
\hline \multicolumn{6}{|c|}{ Second sort: shorting's share of trading volume } & \multicolumn{5}{|c|}{ First sort: shorting's share of trading volume } \\
\hline pf5 - pf1 & -1.13 & -1.99 & -1.56 & -1.60 & -0.83 & 0.19 & -0.32 & -0.19 & 0.26 & -0.27 \\
\hline t-stat & -2.60 & -4.56 & -3.26 & -3.88 & -1.88 & 0.42 & -0.74 & -0.52 & 0.62 & -0.79 \\
\hline
\end{tabular}




\section{Table 5. Different types of short-sellers, and different horizons}

The sample consists of all common stocks listed on the NYSE and extends from January 2000 through April 2004. Firms are sorted into quintiles based on shorting's share of trading volume for the past five days. Average Fama-French alphas for the value-weighted return on the heaviest shorting quintile less that of the lightest shorting quintile are reported for holding the portfolio for the next 5 , 10, 15 and 20 days. T-tests are based on Newey-West standard errors. In Panel B, we obtain NYSE monthly short interest release dates, and omit those days from the portfolio formation process and from the holding period returns. In Panel C, we form a portfolio of stocks with zero shorting during a given formation period and compare it to the heaviest shorting quintile formed from the remaining stocks. Zeroshorting portfolios must contain at least 20 stocks to be included in the excess holding period return time-series average.

Panel A: all dates

\begin{tabular}{|c|c|c|c|c|c|c|c|c|c|c|c|c|c|c|}
\hline \multirow{2}{*}{$\begin{array}{c}\text { Holding } \\
\text { Period }\end{array}$} & \multicolumn{2}{|c|}{ All short sales } & \multicolumn{2}{|c|}{ Individual } & \multicolumn{2}{|c|}{$\begin{array}{c}\text { Institution } \\
\text { Non-program }\end{array}$} & \multicolumn{2}{|c|}{$\begin{array}{c}\text { Institution } \\
\text { Program }\end{array}$} & \multicolumn{2}{|c|}{$\begin{array}{c}\text { Proprietary } \\
\text { Non-program }\end{array}$} & \multicolumn{2}{|c|}{$\begin{array}{c}\text { Proprietary } \\
\text { Program }\end{array}$} & \multicolumn{2}{|c|}{ Other } \\
\hline & alpha & t(alpha) & alpha & t(alpha) & alpha & t(alpha) & alpha & t(alpha) & alpha & t(alpha) & alpha & t(alpha) & alpha & t(alpha) \\
\hline 5 & -0.47 & -5.47 & -0.17 & -1.59 & -0.62 & -6.68 & -0.23 & -2.67 & -0.40 & -4.55 & -0.03 & -0.40 & -0.24 & -3.06 \\
\hline 10 & -0.74 & -5.14 & -0.30 & -1.57 & -1.06 & -6.57 & -0.39 & -2.72 & -0.70 & -4.82 & -0.03 & -0.25 & -0.33 & -2.54 \\
\hline 15 & -1.02 & -5.52 & -0.27 & -1.05 & -1.30 & -6.49 & -0.57 & -2.99 & -0.94 & -4.70 & -0.03 & -0.17 & -0.50 & -2.80 \\
\hline 20 & -1.07 & -5.10 & -0.27 & -0.85 & -1.35 & -6.20 & -0.60 & -2.57 & -1.07 & -4.17 & 0.06 & 0.28 & -0.59 & -2.85 \\
\hline
\end{tabular}

Panel B: skip all short interest release dates

\begin{tabular}{|c|c|c|c|c|c|c|c|c|c|c|c|c|c|c|}
\hline \multirow{2}{*}{$\begin{array}{c}\text { Holding } \\
\text { Period }\end{array}$} & \multicolumn{2}{|c|}{ All short sales } & \multicolumn{2}{|c|}{ Individual } & \multicolumn{2}{|c|}{$\begin{array}{c}\text { Institution } \\
\text { Non Program }\end{array}$} & \multicolumn{2}{|c|}{$\begin{array}{l}\text { Institution } \\
\text { Program }\end{array}$} & \multicolumn{2}{|c|}{$\begin{array}{c}\text { Proprietary } \\
\text { Non Program }\end{array}$} & \multicolumn{2}{|c|}{$\begin{array}{c}\text { Proprietary } \\
\text { Program }\end{array}$} & \multicolumn{2}{|c|}{ Other } \\
\hline & alpha & t(alpha) & alpha & t(alpha) & alpha & t(alpha) & alpha & t(alpha) & alpha & t(alpha) & alpha & t(alpha) & alpha & t(alpha) \\
\hline 5 & -0.44 & -5.05 & -0.20 & -2.01 & -0.62 & -6.73 & -0.27 & -3.27 & -0.34 & -3.82 & -0.04 & -0.52 & -0.22 & -2.92 \\
\hline 10 & -0.70 & -4.76 & -0.32 & -1.72 & -1.02 & -6.05 & -0.44 & -3.23 & -0.57 & -4.06 & -0.06 & -0.45 & -0.29 & -2.40 \\
\hline 15 & -0.97 & -5.16 & -0.29 & -1.17 & -1.26 & -5.98 & -0.61 & -3.44 & -0.76 & -3.85 & -0.05 & -0.26 & -0.48 & -2.78 \\
\hline 20 & -1.05 & -4.80 & -0.27 & -0.86 & -1.36 & -5.54 & -0.57 & -2.56 & -0.83 & -3.30 & -0.04 & -0.17 & -0.52 & -2.60 \\
\hline
\end{tabular}

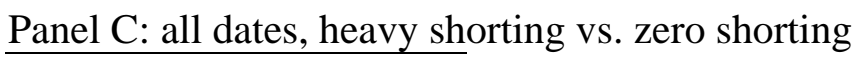

\begin{tabular}{ccc}
\hline & \multicolumn{2}{c}{ Individual } \\
\cline { 2 - 3 } Holding & & \\
\cline { 2 - 3 } Period & alpha & $\mathrm{t}$ (alpha) \\
5 & -0.23 & -2.53 \\
10 & -0.39 & -2.37 \\
15 & -0.41 & -1.80 \\
20 & -0.54 & -1.95 \\
\hline
\end{tabular}




\section{Table 6. Multiple regression analysis of shorting by different account types}

Fama-MacBeth regressions for daily observations on all common stocks listed on the NYSE, Jan 2000 Apr 2004. Explanatory variables are shorting turnover (shares shorted by the specified account type divided by NYSE volume in that stock) for the past five days. The t-statistics are reported below the parameter estimates and are based on the time-series of coefficient estimates from the cross-sectional regressions using Newey-West.

Panel A: Dependent variable is the return one day ahead

\begin{tabular}{|c|c|c|c|c|c|c|c|c|}
\hline & \multirow[t]{2}{*}{ Intercept } & \multirow[t]{2}{*}{ Individuals } & \multicolumn{2}{|c|}{ Institutions } & \multicolumn{2}{|c|}{ Proprietary } & \multirow[t]{2}{*}{ Other } & \multirow[t]{2}{*}{ adj. $R^{2}$} \\
\hline & & & $\begin{array}{c}\text { Non- } \\
\text { program }\end{array}$ & Program & $\begin{array}{c}\text { Non- } \\
\text { program }\end{array}$ & Program & & \\
\hline \multirow[t]{2}{*}{ Model 1} & 0.04 & -4.26 & & & & & & $0.11 \%$ \\
\hline & 4.41 & -3.99 & & & & & & \\
\hline \multirow[t]{2}{*}{ Model 2} & 0.11 & & -1.08 & & & & & $0.13 \%$ \\
\hline & 10.59 & & -12.41 & & & & & \\
\hline \multirow[t]{2}{*}{ Model 3} & 0.05 & & & -0.74 & & & & $0.06 \%$ \\
\hline & 5.04 & & & -5.14 & & & & \\
\hline \multirow[t]{2}{*}{ Model 4} & 0.05 & & & & -1.15 & & & $0.09 \%$ \\
\hline & 5.76 & & & & -4.75 & & & \\
\hline \multirow[t]{2}{*}{ Model 5} & 0.04 & & & & & -0.42 & & $0.10 \%$ \\
\hline & 4.37 & & & & & -1.34 & & \\
\hline \multirow[t]{2}{*}{ Model 6} & 0.05 & & & & & & -2.65 & $0.09 \%$ \\
\hline & 4.74 & & & & & & -4.08 & \\
\hline \multirow[t]{2}{*}{ Model 7} & 0.12 & -2.64 & -0.94 & -0.37 & -0.44 & 0.55 & -1.63 & $0.52 \%$ \\
\hline & 10.77 & -2.54 & -10.54 & -2.56 & -1.73 & 1.81 & -2.54 & \\
\hline
\end{tabular}

Panel B: Dependent variable is the return $[+1,+20]$

\begin{tabular}{|c|c|c|c|c|c|c|c|c|}
\hline & \multirow[t]{2}{*}{ Intercept } & \multirow[t]{2}{*}{ Individuals } & \multicolumn{2}{|c|}{ Institutions } & \multicolumn{2}{|c|}{ Proprietary } & \multirow[t]{2}{*}{ Other } & \multirow[t]{2}{*}{ adj. $R^{2}$} \\
\hline & & & $\begin{array}{c}\text { Non- } \\
\text { program }\end{array}$ & Program & $\begin{array}{c}\text { Non- } \\
\text { program }\end{array}$ & Program & & \\
\hline \multirow[t]{2}{*}{ Model 1} & 0.70 & -32.00 & & & & & & $0.12 \%$ \\
\hline & 5.50 & -2.66 & & & & & & \\
\hline \multirow[t]{2}{*}{ Model 2} & 1.47 & & -12.63 & & & & & $0.32 \%$ \\
\hline & 10.76 & & -10.19 & & & & & \\
\hline \multirow[t]{2}{*}{ Model 3} & 0.83 & & & -10.24 & & & & $0.14 \%$ \\
\hline & 6.59 & & & -4.18 & & & & \\
\hline \multirow[t]{2}{*}{ Model 4} & 0.92 & & & & -12.81 & & & $0.20 \%$ \\
\hline & 7.12 & & & & -3.74 & & & \\
\hline \multirow[t]{2}{*}{ Model 5} & 0.74 & & & & & -4.88 & & $0.11 \%$ \\
\hline & 6.30 & & & & & -1.26 & & \\
\hline \multirow[t]{2}{*}{ Model 6} & 0.79 & & & & & & -24.49 & $0.13 \%$ \\
\hline & 6.00 & & & & & & -3.00 & \\
\hline \multirow[t]{2}{*}{ Model 7} & 1.65 & -15.07 & -11.11 & -6.15 & -4.19 & 6.46 & -11.43 & $0.86 \%$ \\
\hline & 12.28 & -1.31 & -9.20 & -2.51 & -1.18 & 1.62 & -1.39 & \\
\hline
\end{tabular}


Table 7. Time-series patterns in shorting by account type

Fama-MacBeth regressions for daily observations on all common stocks listed on the NYSE, Jan 2000 - Apr 2004 . Explanatory variables are shorting's share of volume (shares shorted by the specified account type divided by total NYSE volume in that stock) for the previous day. The t-statistics are reported below the parameter estimates and are based on the time-series of coefficient estimates from the cross-sectional regressions using Newey-West.

\begin{tabular}{|c|c|c|c|c|c|c|c|c|}
\hline \multirow[t]{2}{*}{ Dep. Var } & \multirow[t]{2}{*}{ Intercept } & \multirow{2}{*}{$\begin{array}{c}\text { Lag } \\
\text { Individuals }\end{array}$} & \multicolumn{2}{|c|}{ Lag Institutions } & \multicolumn{2}{|c|}{ Lag Proprietary } & \multirow[t]{2}{*}{ Lag Other } & \multirow[t]{2}{*}{ adj. $\mathrm{R}^{2}$} \\
\hline & & & Non-program & Program & Non-program & Program & & \\
\hline \multirow[t]{2}{*}{ Individual } & $0.1 \%$ & 0.224 & 0.004 & -0.002 & 0.001 & -0.002 & 0.008 & $7.5 \%$ \\
\hline & 50.02 & 33.26 & 20.75 & -8.90 & 3.27 & -3.11 & 6.34 & \\
\hline Institution & $3.4 \%$ & 0.271 & 0.403 & 0.095 & 0.116 & 0.091 & 0.142 & $18.8 \%$ \\
\hline Non-program & 128.38 & 21.46 & 193.18 & 45.68 & 35.00 & 22.95 & 21.13 & \\
\hline Institution & $1.3 \%$ & -0.039 & 0.027 & 0.398 & 0.025 & 0.089 & 0.017 & $18.2 \%$ \\
\hline Program & 120.72 & -7.69 & 39.49 & 157.24 & 14.43 & 33.67 & 4.27 & \\
\hline Proprietary & $0.7 \%$ & 0.009 & 0.021 & 0.019 & 0.319 & 0.028 & 0.024 & $12.4 \%$ \\
\hline Non-program & 93.34 & 2.22 & 39.92 & 20.15 & 86.66 & 17.24 & 11.38 & \\
\hline Proprietary & $0.6 \%$ & -0.013 & 0.012 & 0.034 & 0.015 & 0.415 & 0.012 & $19.9 \%$ \\
\hline Program & 62.90 & -4.15 & 25.66 & 38.16 & 13.87 & 96.98 & 4.54 & \\
\hline \multirow[t]{2}{*}{ Other } & $0.4 \%$ & 0.014 & 0.006 & 0.006 & 0.006 & 0.007 & 0.254 & $8.2 \%$ \\
\hline & 69.99 & 6.83 & 20.82 & 11.93 & 9.14 & 7.64 & 54.00 & \\
\hline
\end{tabular}




\section{Table 8. Summary statistics on characteristics}

The sample consists of all common stocks listed on the NYSE and extends from January 2000 through April 2004. All shorting measures are shorting's share of volume, which is shares sold short on a given day as a percentage of NYSE trading volume in that stock on that day. Iret5 is the return over the past five trading days. sigma is daily return volatility for the previous month. es is the transaction-weighted effective spread in $\$$ for that day. omkt is the fraction of short sales executed via marketable orders on that day. For each stock each day, lon1, lon2, lon3, lon4, and lon5 are the percentages of the number of shorting orders with order size smaller than 500 shares, between 500 and 1,999 shares, between 2,000 and 4,999 shares, between 5,000 and 9,999 shares, and at least 10,000 shares respectively.

Panel A. time-series average of cross-sectional average

\begin{tabular}{l|ccccc}
\hline & mean & stdev & p25 & median & p75 \\
\hline Ln(mktcap) & 14.4510 & 1.5248 & 13.3819 & 14.2761 & 15.3930 \\
Book/mkt & 0.7143 & 0.9216 & 0.3201 & 0.5325 & 0.8517 \\
lret5 & 0.0042 & 0.0628 & -0.0249 & 0.0033 & 0.0324 \\
sigma & 0.3439 & 0.2185 & 0.2153 & 0.2920 & 0.4070 \\
turnover & 0.0051 & 0.0063 & 0.0021 & 0.0035 & 0.0060 \\
es & 0.0525 & 0.0537 & 0.0344 & 0.0440 & 0.0590 \\
omkt & 0.4189 & 0.2248 & 0.2763 & 0.4054 & 0.5440 \\
lon1 & $50 \%$ & $18 \%$ & $37 \%$ & $49 \%$ & $62 \%$ \\
lon2 & $31 \%$ & $12 \%$ & $22 \%$ & $31 \%$ & $39 \%$ \\
lon3 & $10 \%$ & $8 \%$ & $5 \%$ & $9 \%$ & $14 \%$ \\
lon4 & $5 \%$ & $6 \%$ & $1 \%$ & $3 \%$ & $7 \%$ \\
lon5 & $4 \%$ & $8 \%$ & $0 \%$ & $2 \%$ & $6 \%$ \\
\hline
\end{tabular}

Panel B: Shorting at various order sizes by account type

\begin{tabular}{ccccccc}
\hline \multirow{2}{*}{$\begin{array}{c}\text { Order size } \\
\text { (in shares) }\end{array}$} & Individual & \multicolumn{7}{c}{ Institution } & \multicolumn{3}{c}{ Proprietary } & Other \\
\cline { 2 - 6 } & & Non-prog. & Program & Non-prog. & Program & \\
\hline $1-499$ & $1 \%$ & $32 \%$ & $26 \%$ & $15 \%$ & $19 \%$ & $8 \%$ \\
$500-1,999$ & $1 \%$ & $51 \%$ & $19 \%$ & $10 \%$ & $11 \%$ & $7 \%$ \\
$2,000-4,999$ & $2 \%$ & $53 \%$ & $20 \%$ & $10 \%$ & $7 \%$ & $9 \%$ \\
$5,000-9,999$ & $2 \%$ & $52 \%$ & $14 \%$ & $11 \%$ & $4 \%$ & $17 \%$ \\
$10,000-$ & $1 \%$ & $45 \%$ & $8 \%$ & $13 \%$ & $2 \%$ & $31 \%$ \\
\cline { 2 - 6 } & $1 \%$ & \multicolumn{6}{c}{ Average short sale order size (in shares) } \\
\cline { 2 - 7 } & 820 & 743 & 550 & 729 & 398 & 1,015
\end{tabular}


Panel C. Correlation with shorting measures from different account types

\begin{tabular}{l|ccccccc}
\hline & All short & Indi & Inst. NP & Inst. P & Prop. NP & Prop. P & Other \\
\hline ln(mktcap) & $-1 \%$ & $-2 \%$ & $4 \%$ & $-4 \%$ & $6 \%$ & $-17 \%$ & $6 \%$ \\
book/mkt & $-2 \%$ & $0 \%$ & $-3 \%$ & $-1 \%$ & $-2 \%$ & $3 \%$ & $-1 \%$ \\
lret5 & $20 \%$ & $1 \%$ & $14 \%$ & $12 \%$ & $9 \%$ & $15 \%$ & $12 \%$ \\
sigma & $-7 \%$ & $8 \%$ & $-1 \%$ & $-16 \%$ & $-2 \%$ & $-3 \%$ & $3 \%$ \\
turnover & $3 \%$ & $9 \%$ & $9 \%$ & $-10 \%$ & $2 \%$ & $-4 \%$ & $1 \%$ \\
es & $0 \%$ & $3 \%$ & $0 \%$ & $0 \%$ & $-1 \%$ & $2 \%$ & $-1 \%$ \\
omkt & $7 \%$ & $4 \%$ & $5 \%$ & $3 \%$ & $2 \%$ & $7 \%$ & $2 \%$ \\
lon1 & $-14 \%$ & $-10 \%$ & $-26 \%$ & $9 \%$ & $-9 \%$ & $16 \%$ & $-7 \%$ \\
lon2 & $11 \%$ & $0 \%$ & $12 \%$ & $3 \%$ & $6 \%$ & $-3 \%$ & $5 \%$ \\
lon3 & $8 \%$ & $7 \%$ & $14 \%$ & $-4 \%$ & $6 \%$ & $-10 \%$ & $6 \%$ \\
lon4 & $7 \%$ & $11 \%$ & $19 \%$ & $-11 \%$ & $6 \%$ & $-14 \%$ & $4 \%$ \\
lon5 & $4 \%$ & $8 \%$ & $16 \%$ & $-15 \%$ & $5 \%$ & $-16 \%$ & $2 \%$ \\
\hline
\end{tabular}

Panel D. Correlation among characteristics

\begin{tabular}{|c|c|c|c|c|c|c|c|c|c|c|c|}
\hline & bm & lret5 & sigma & turnover & es & omkt & lon1 & lon2 & $\operatorname{lon} 3$ & lon4 & lon5 \\
\hline $\ln$ (mktcap) & $-31 \%$ & $-1 \%$ & $-31 \%$ & $0 \%$ & $-15 \%$ & $-1 \%$ & $-31 \%$ & $25 \%$ & $18 \%$ & $12 \%$ & $11 \%$ \\
\hline book/mkt & & $-4 \%$ & $28 \%$ & $1 \%$ & $-5 \%$ & $0 \%$ & $-5 \%$ & $-7 \%$ & $3 \%$ & $7 \%$ & $15 \%$ \\
\hline lret5 & & & $1 \%$ & $-3 \%$ & $2 \%$ & $-1 \%$ & $2 \%$ & $7 \%$ & $-1 \%$ & $-7 \%$ & $-10 \%$ \\
\hline sigma & & & & $27 \%$ & $-2 \%$ & $1 \%$ & $-20 \%$ & $-2 \%$ & $13 \%$ & $17 \%$ & $23 \%$ \\
\hline turnover & & & & & $-2 \%$ & $4 \%$ & $-16 \%$ & $6 \%$ & $10 \%$ & $12 \%$ & $13 \%$ \\
\hline es & & & & & & $-1 \%$ & $25 \%$ & $-13 \%$ & $-16 \%$ & $-12 \%$ & $-14 \%$ \\
\hline omkt & & & & & & & $-5 \%$ & $-1 \%$ & $5 \%$ & $5 \%$ & $4 \%$ \\
\hline lon1 & & & & & & & & $-57 \%$ & $-62 \%$ & $-52 \%$ & $-49 \%$ \\
\hline lon2 & & & & & & & & & $8 \%$ & $-10 \%$ & $-15 \%$ \\
\hline lon3 & & & & & & & & & & $31 \%$ & $16 \%$ \\
\hline lon4 & & & & & & & & & & & $37 \%$ \\
\hline
\end{tabular}


Table 9. Double sort on total shorted shares and prevalence of given short order size

Firms are first sorted into quintiles based on the past 5-day total shares shorted (vall). Within each quintile, firms are then sorted into quintiles based on lon1 - lon5, the prevalence of a given order size among short orders for the past five days. For each stock, lon1- lon5 are the fraction of the number of shorting orders with order size smaller than 500 shares, between 500 and 1,999 shares, between 2,000 and 4,999 shares, between 5,000 and 9,999 shares, and at least 10,000 shares respectively. Mean excess returns and Fama-French alphas for average value-weighted return differences are reported for holding the portfolio for the next 20 days. T-tests are based on Newey-West standard errors.

\begin{tabular}{|c|c|c|c|c|c|c|c|c|c|c|}
\hline & \multicolumn{5}{|c|}{ Mean excess returns } & \multicolumn{5}{|c|}{ FF alphas } \\
\hline & $\begin{array}{l}\text { low } \\
\text { vall }\end{array}$ & 2 & 3 & 4 & $\begin{array}{l}\text { high } \\
\text { vall }\end{array}$ & $\begin{array}{l}\text { low } \\
\text { vall }\end{array}$ & 2 & 3 & 4 & $\begin{array}{l}\text { high } \\
\text { vall }\end{array}$ \\
\hline \multicolumn{11}{|c|}{ First sort on vall, second sort on lon1 } \\
\hline lo lon1 & 0.72 & 0.03 & -0.53 & -0.33 & 0.35 & 1.17 & 0.50 & -0.21 & -0.26 & 0.02 \\
\hline 2 & 1.14 & 0.06 & -0.30 & -0.19 & 0.32 & 1.45 & 0.29 & -0.07 & -0.02 & 0.13 \\
\hline 3 & 1.22 & 0.28 & -0.14 & 0.25 & 0.62 & 1.43 & 0.43 & 0.06 & 0.22 & 0.41 \\
\hline 4 & 1.66 & 0.53 & 0.47 & 0.56 & 0.74 & 1.37 & 0.53 & 0.23 & 0.40 & 0.46 \\
\hline hi lon1 & 2.28 & 1.52 & 1.02 & 1.01 & 0.91 & 1.88 & 1.22 & 0.76 & 0.69 & 0.50 \\
\hline port 5-1 & 1.56 & 1.49 & 1.55 & 1.33 & 0.56 & 0.70 & 0.72 & 0.96 & 0.94 & 0.47 \\
\hline $\mathrm{t}$ & 3.30 & 3.67 & 4.48 & 4.52 & 1.78 & 1.97 & 1.97 & 2.91 & 4.06 & 1.70 \\
\hline \multicolumn{11}{|c|}{ First sort on vall, second sort on lon2 } \\
\hline lo lon2 & 2.14 & 0.63 & 0.58 & 0.56 & 0.72 & 1.92 & 0.59 & 0.35 & 0.45 & 0.27 \\
\hline 2 & 0.88 & -0.12 & -0.33 & 0.02 & 0.21 & 1.17 & 0.11 & -0.27 & -0.07 & -0.14 \\
\hline 3 & 1.02 & 0.28 & -0.45 & -0.01 & 0.43 & 1.46 & 0.63 & -0.29 & -0.05 & 0.25 \\
\hline 4 & 0.99 & 0.21 & -0.24 & 0.04 & 0.66 & 1.19 & 0.38 & 0.00 & -0.07 & 0.35 \\
\hline hi lon2 & 1.48 & 0.77 & 0.29 & 0.21 & 0.58 & 1.58 & 0.76 & 0.27 & 0.12 & 0.23 \\
\hline port 5-1 & -0.66 & 0.15 & -0.29 & -0.35 & -0.14 & -0.35 & 0.17 & -0.08 & -0.33 & -0.04 \\
\hline $\mathrm{t}$ & -1.86 & 0.36 & -0.74 & -0.97 & -0.45 & -0.99 & 0.40 & -0.21 & -0.87 & -0.11 \\
\hline \multicolumn{11}{|c|}{ First sort on vall, second sort on lon3 } \\
\hline lo lon3 & 2.64 & 1.37 & 0.96 & 0.91 & 1.14 & 2.20 & 1.11 & 0.67 & 0.54 & 0.78 \\
\hline 2 & 1.72 & 0.82 & 0.34 & 0.57 & 0.57 & 1.58 & 0.76 & 0.26 & 0.59 & 0.26 \\
\hline 3 & 1.06 & 0.21 & -0.14 & -0.17 & 0.49 & 1.17 & 0.41 & 0.18 & -0.03 & 0.40 \\
\hline 4 & 0.98 & 0.05 & -0.31 & -0.11 & 0.19 & 1.24 & 0.42 & -0.11 & -0.07 & 0.00 \\
\hline hi lon3 & 0.83 & 0.17 & -0.30 & -0.11 & 0.46 & 1.36 & 0.45 & -0.22 & -0.28 & -0.01 \\
\hline port 5-1 & -1.80 & -1.20 & -1.26 & -1.02 & -0.68 & -0.84 & -0.65 & -0.90 & -0.82 & -0.79 \\
\hline $\mathrm{t}$ & -3.75 & -3.50 & -3.72 & -4.07 & -2.48 & -2.33 & -2.06 & -2.72 & -3.18 & -3.02 \\
\hline \multicolumn{11}{|c|}{ First sort on vall, second sort on lon4 } \\
\hline lo lon4 & 2.82 & 1.88 & 1.52 & 1.16 & 1.23 & 2.32 & 1.43 & 1.14 & 0.75 & 0.68 \\
\hline 2 & 1.76 & 1.09 & 0.77 & 0.78 & 0.96 & 1.47 & 0.91 & 0.53 & 0.61 & 0.54 \\
\hline 3 & 1.29 & -0.03 & -0.37 & 0.05 & 0.67 & 1.42 & 0.04 & 0.01 & -0.22 & 0.17 \\
\hline 4 & 1.13 & 0.18 & -0.87 & -0.33 & 0.47 & 1.58 & 0.55 & -0.80 & -0.18 & 0.22 \\
\hline hi lon4 & 0.73 & -0.42 & -0.64 & -0.23 & 0.35 & 1.31 & 0.26 & -0.15 & 0.03 & 0.19 \\
\hline port 5-1 & -2.09 & -2.30 & -2.15 & -1.40 & -0.88 & -1.01 & -1.17 & -1.29 & -0.71 & -0.49 \\
\hline $\mathrm{t}$ & -3.04 & -4.21 & -4.08 & -3.09 & -2.21 & -2.03 & -3.15 & -3.31 & -2.72 & -1.47 \\
\hline \multicolumn{11}{|c|}{ First sort on vall, second sort on lon5 } \\
\hline lo lon5 & 3.16 & 2.85 & 2.39 & 2.07 & 2.11 & 2.16 & 1.73 & 1.22 & 1.03 & 0.85 \\
\hline 2 & 2.54 & 1.63 & 1.39 & 1.55 & 1.73 & 1.67 & 0.58 & 0.39 & 0.61 & 0.49 \\
\hline 3 & 2.13 & 0.89 & 0.61 & 1.30 & 1.67 & 1.54 & 0.39 & -0.13 & 0.63 & 0.69 \\
\hline 4 & 1.46 & 0.91 & -0.24 & 0.71 & 1.17 & 1.00 & 0.50 & -0.39 & 0.13 & 0.13 \\
\hline hi lon5 & 1.38 & 0.31 & -0.09 & 0.18 & 0.71 & 1.10 & 0.23 & -0.44 & -0.20 & -0.18 \\
\hline port 5-1 & -1.78 & -2.54 & -2.48 & -1.89 & -1.40 & -1.05 & -1.49 & -1.66 & -1.23 & -1.03 \\
\hline $\mathrm{t}$ & -2.25 & -4.13 & -5.21 & -4.93 & -3.70 & -1.34 & -3.18 & -4.43 & -4.79 & -3.57 \\
\hline
\end{tabular}




\section{Table 10. Predictive regressions with characteristic controls}

Fama-MacBeth regressions of daily observations for all common stocks listed on the NYSE, Jan 2000 through Apr 2004. The dependent variable is the cumulative Fama-French three-factor alpha over the following 20 trading days. Shorting share is defined as shares sold short as a percentage of NYSE volume in that stock. Return volatility is calculated over the previous month. omkt is the fraction of short sales executed via marketable orders on a given day. For each stock each day, lon1, lon2, lon3 and lon4 are the percentages of the number of shorting orders with order size smaller than 500 shares, between 500 and 1,999 shares, between 2,000 and 4,999 shares, and between 5,000 and 9,999 shares, respectively. The t-statistics are reported below the parameter estimates and are based on the time-series of coefficient estimates from the cross-sectional regressions using Newey-West.

\begin{tabular}{|c|c|c|c|c|c|c|c|c|c|c|c|c|c|c|}
\hline & Intercept & $\begin{array}{c}\text { Shorting } \\
\text { share }\end{array}$ & $\begin{array}{c}\text { Log } \\
\text { mktcap }\end{array}$ & $\begin{array}{c}\text { Book } \\
\text { to } \\
\text { market }\end{array}$ & $\begin{array}{c}\text { Return } \\
\text { volatility }\end{array}$ & $\begin{array}{c}\text { Lagged } \\
\text { 5-day } \\
\text { return }\end{array}$ & Turnover & $\begin{array}{c}\text { Effective } \\
\text { spread }\end{array}$ & omkt & lon1 & lon2 & lon3 & lon4 & $\operatorname{adj} R^{2}$ \\
\hline \multirow[t]{2}{*}{ All shorts } & 5.64 & -7.28 & -0.25 & -0.65 & 0.86 & -0.01 & -0.09 & 0.22 & -0.14 & 0.15 & -0.72 & 0.20 & -0.21 & $5.85 \%$ \\
\hline & 4.32 & -9.88 & -4.31 & -3.37 & 1.02 & -0.99 & -0.88 & 0.10 & -0.93 & 0.16 & -0.65 & 0.18 & -0.19 & \\
\hline \multirow[t]{2}{*}{ Individual } & 3.62 & -22.38 & -0.19 & -0.63 & 1.31 & -0.04 & -0.08 & -0.51 & -0.30 & 0.70 & -0.86 & 0.12 & -0.35 & $5.66 \%$ \\
\hline & 2.88 & -2.07 & -3.40 & -3.29 & 1.55 & -2.86 & -0.79 & -0.23 & -1.98 & 0.72 & -0.79 & 0.12 & -0.30 & \\
\hline Institution & 5.91 & -12.40 & -0.23 & -0.67 & 0.89 & -0.02 & -0.06 & 0.87 & -0.24 & -0.64 & -1.25 & -0.49 & -0.27 & $5.88 \%$ \\
\hline Non-prog & 4.47 & -9.83 & -4.16 & -3.47 & 1.06 & -1.38 & -0.56 & 0.42 & -1.57 & -0.64 & -1.13 & -0.45 & -0.24 & \\
\hline Institution & 3.50 & -5.62 & -0.19 & -0.63 & 1.30 & -0.03 & -0.08 & -0.91 & -0.31 & 0.98 & -0.68 & 0.13 & -0.49 & $5.68 \%$ \\
\hline Program & 2.73 & -1.29 & -3.32 & -3.25 & 1.55 & -2.54 & -0.79 & -0.43 & -2.08 & 0.98 & -0.62 & 0.13 & -0.43 & \\
\hline Proprietary & 3.71 & -11.05 & -0.18 & -0.64 & 1.24 & -0.03 & -0.09 & -0.34 & -0.33 & 0.66 & -0.84 & 0.17 & -0.45 & $5.69 \%$ \\
\hline Non-prog. & 2.94 & -3.95 & -3.30 & -3.30 & 1.48 & -2.58 & -0.83 & -0.16 & -2.13 & 0.68 & -0.78 & 0.15 & -0.39 & \\
\hline Proprietary & 3.93 & -9.91 & -0.21 & -0.62 & 1.08 & -0.03 & -0.12 & -0.87 & -0.25 & 1.06 & -0.41 & 0.63 & -0.30 & $5.67 \%$ \\
\hline Program & 3.05 & -5.15 & -3.67 & -3.24 & 1.28 & -2.34 & -1.16 & -0.41 & -1.61 & 1.08 & -0.38 & 0.57 & -0.27 & \\
\hline \multirow[t]{2}{*}{ Other } & 3.53 & -20.67 & -0.18 & -0.64 & 1.31 & -0.03 & -0.09 & -0.62 & -0.32 & 0.79 & -0.72 & 0.26 & -0.41 & $5.66 \%$ \\
\hline & 2.80 & -2.95 & -3.29 & -3.31 & 1.57 & -2.57 & -0.87 & -0.29 & -2.11 & 0.81 & -0.66 & 0.24 & -0.36 & \\
\hline
\end{tabular}


Figure 1. Risk-adjusted return differences on short-sale portfolios of different account types

The sample consists of all common stocks listed on the NYSE and extends from January 2000 through April 2004. Firms are sorted into quintiles based on the shorting activity over the past five days (shares sold short as a percentage of NYSE trading volume). We show average Fama-French alphas for the next 20 days for value-weighted return differences. Alphas are based on the heaviest shorting quintile less the lightest shorting quintile and are expressed in percent.

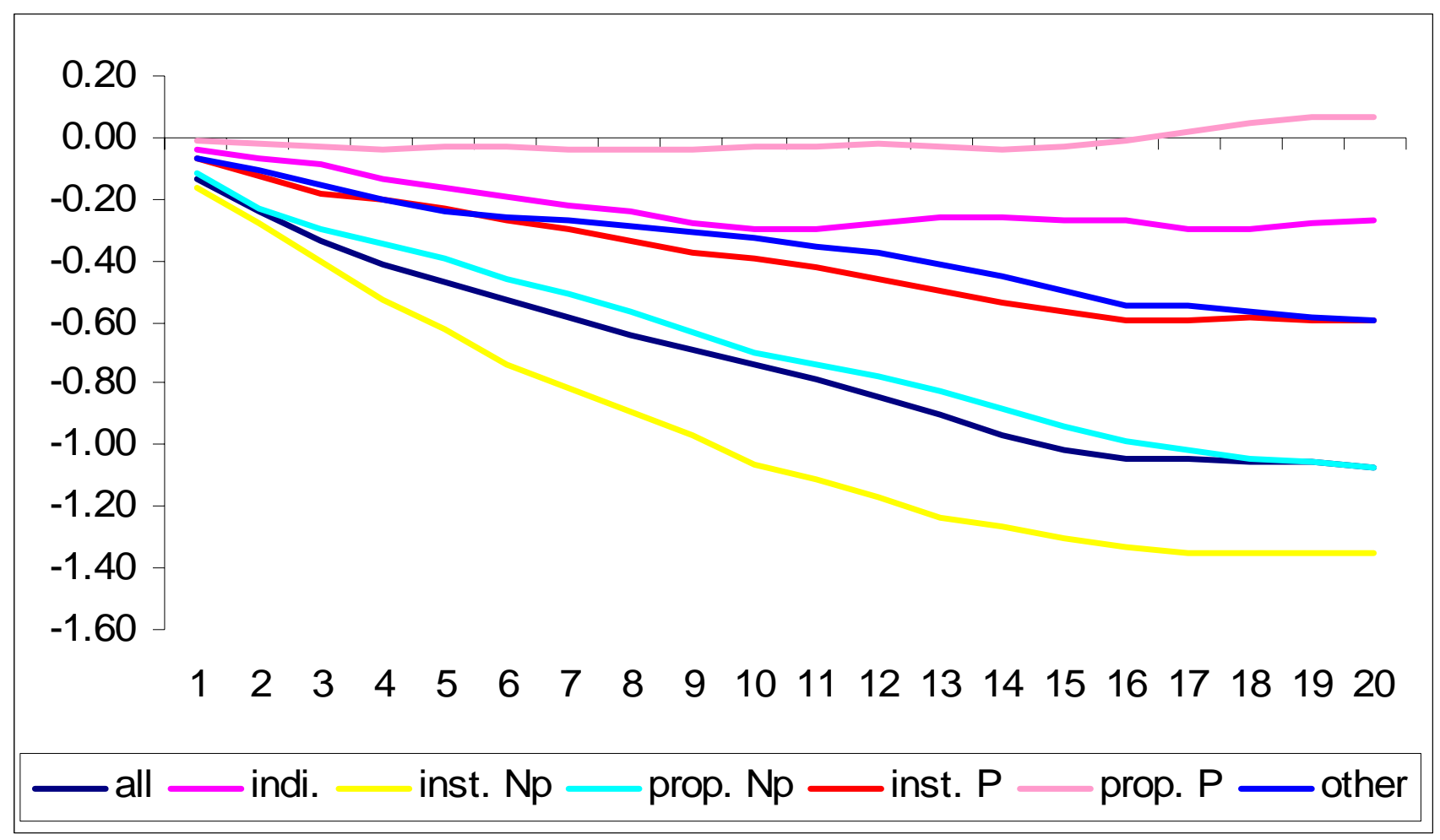




\section{Figure 2. Return differences on short-sale portfolios}

The sample consists of all common stocks listed on the NYSE and extends from January 2000 through April 2004. Firms are first sorted into quintiles based on shorting activity over the past five trading days (shares sold short as a percentage of NYSE trading volume). The figure reports average value-weighted return differences (quintile 5 - quintile 1) for the next 20 days (using non-overlapping periods only). Institutional and proprietary shorting measures exclude executions that are part of a program trade.

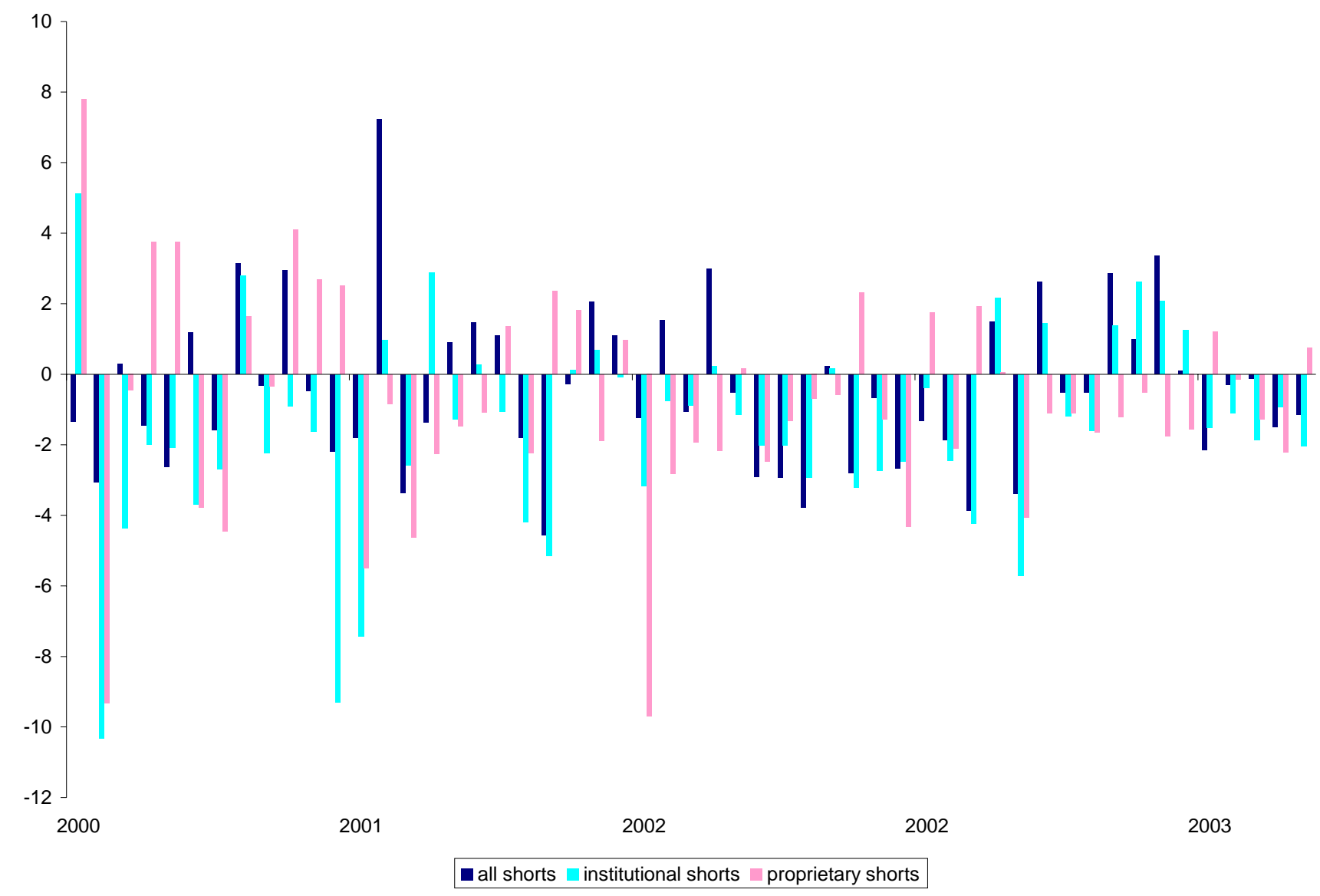

